NBER WORKING PAPER SERIES

\title{
AUSTERITY IN THE AFTERMATH OF THE GREAT RECESSION
}

\author{
Christopher L. House \\ Christian Proebsting \\ Linda L. Tesar \\ Working Paper 23147 \\ http://www.nber.org/papers/w23147 \\ NATIONAL BUREAU OF ECONOMIC RESEARCH \\ 1050 Massachusetts Avenue \\ Cambridge, MA 02138 \\ February 2017
}

We thank Karel Mertens, Bartosz Mackowiak, Thomas Philippon and Efrem Castelnuovo for excellent feedback and suggestions. We also thank seminar participants at the ASSA 2017 meeting, Brigham Young University, Boston University, Boston College, DIW, the ECB, the EEA summer meeting, the Federal Reserve Bank of Cleveland, the Graduate Institute of Geneva, the University of Lausanne, New York University, the NBER summer institute, the RBA macroeconomic workshop in Sydney, and the University of Michigan. We gratefully acknowledge financial support from the Michigan Institute for Teaching and Research in Economics (MITRE). The views expressed herein are those of the authors and do not necessarily reflect the views of the National Bureau of Economic Research.

NBER working papers are circulated for discussion and comment purposes. They have not been peer-reviewed or been subject to the review by the NBER Board of Directors that accompanies official NBER publications.

(C) 2017 by Christopher L. House, Christian Proebsting, and Linda L. Tesar. All rights reserved. Short sections of text, not to exceed two paragraphs, may be quoted without explicit permission provided that full credit, including $(\subset$ notice, is given to the source. 
Austerity in the Aftermath of the Great Recession

Christopher L. House, Christian Proebsting, and Linda L. Tesar

NBER Working Paper No. 23147

February 2017

JEL No. E00,E62,F41,F44,F45

\begin{abstract} a consequence of endogenous reductions in GDP and tax revenue.

Christopher L. House

University of Michigan

Department of Economics

238 Lorch Hall

Ann Arbor, MI 48109-1220

and NBER

chouse@umich.edu

Christian Proebsting

École Polytechnique Fédérale de Lausanne

CH-1015 Lausanne

Switzerland

cproebsting@gmail.com

Linda L. Tesar

Department of Economics

University of Michigan

Ann Arbor, MI 48109-1220

and NBER

ltesar@umich.edu
\end{abstract}

We examine austerity in advanced economies since the Great Recession. Austerity shocks are reductions in government purchases that exceed reduced-form forecasts. Austerity shocks are statistically associated with lower real GDP, lower inflation and higher net exports. We estimate a cross-sectional multiplier of roughly 2. A multi-country DSGE model calibrated to 29 advanced economies generates a multiplier consistent with the data. Counterfactuals suggest that eliminating austerity would have substantially reduced output losses in Europe. Austerity shocks were sufficiently contractionary that debt-to-GDP ratios in some European countries increased as

A appendices is available at http://www.nber.org/data-appendix/w23147 


\section{Introduction}

The economies in Europe contracted sharply and almost synchronously during the global financial crisis. In the aftermath of the crisis, however, economic performance has varied. An open question is whether differences in rates of recovery are due to differences in the severity of external shocks, the policy reactions to the shocks, or the economic conditions at the time of the crisis. The financial press and many economists have attributed at least some of the slow rate of recovery to austerity policies that cut government expenditures and increased tax rates at precisely the time when faltering economies required stimulus. This paper shows that contractions in government purchases can in fact account for much of the divergence in national economic performance since the Great Recession.

Figure 1 plots real per capita GDP for 29 countries including the U.S., countries in the European Union, Switzerland, and Norway. The data is normalized so that per capita GDP is 100 in 2009:2 for every country. The figure also plots per capita GDP for the European aggregate. Overall, the aggregate European experience is similar to that of the United States. This similarity, however, masks a tremendous amount of variation across Europe. At one end of the spectrum is Greece, for which the "recovery" never began. Greek per capita income at the end of 2014 is more than 25 percent below its 2009 level. While Greece's GDP performance is exceptionally negative, a contraction in GDP over this period is not unique. About a third of the countries have end-2014 levels of real per capita GDP at or below their 2009 levels. At the other end of the spectrum is Lithuania. Like Greece, Lithuania experienced a strong contraction during the Great Recession. However, it then returned to a rapid rate of growth quickly thereafter.

Our goal is to document cross-country differences in economic performance since 2010 and to study the extent to which the differences can be explained by macroeconomic policy. We first construct measures of austerity shocks that occurred during the 2010 to 2014 period. We find that austerity in government purchases - defined as a reduction in government purchases that is larger than that implied by reduced-form forecasting regressions is statistically associated with below-forecast GDP in the cross-section. The cross-sectional multiplier on government purchases is greater than one even after controlling for alternative measures of credit spreads and debt ratios. The negative relationship between austerity in government purchases and GDP is robust to the method used to forecast both GDP and government purchases in the 2010 to 2014 period, and holds for countries with fixed exchange 
rates as well as those with flexible exchange rates. Austerity in government purchases is also negatively associated with consumption, investment, GDP growth and inflation. In terms of international variables, a shortfall in government purchases is associated with an increase in net exports and a depreciation of the trade-weighted nominal exchange rate. In general, these relationships are robust to the country's exchange rate regime though, not surprisingly, the impact on exchange rates is smaller and the impact on net exports larger for countries within the euro area and those with exchange rates fixed to the euro.

We develop a multi-country DSGE model to make comparisons between the predictions from our model and macroeconomic data for 2010-2014. The model features trade in intermediate goods, sticky prices, hand-to-mouth consumers, and financial frictions that drive a wedge between the marginal product of capital and the user cost of capital. The model is calibrated to reflect relative country size, trade flows and financial linkages, and the country's exchange rate regime. The model incorporates shocks to government purchases, the cost of credit, and monetary policy. We focus on these three shocks because there is broad agreement that these factors played an important role in shaping the reaction to the Great Recession.

The benchmark model generates predictions that are consistent with data. In both the cross-sectional data and the model, a one percent reduction in government purchases is associated with a two percent reduction in GDP. As in the data, the model generates a positive relationship between austerity and net exports and a strong negative relationship between austerity and inflation. Among the features that are essential to generate large cross-sectional spending multipliers are hand-to-mouth consumers, consumption-labor complementarity in the utility function (Greenwood, Hercowitz and Huffman, 1988) and significant trade linkages. The zero lower bound (ZLB) plays an important role in generating a large time-series multiplier but has virtually no influence on the magnitude of the cross-sectional multiplier.

We use our model to conduct a number of counterfactual experiments. The model suggests that had countries not experienced austerity shocks, aggregate output in the EU10 ${ }^{1}$ would have been only roughly equal to its pre-crisis level rather than an output loss of 3 percent. The output losses in the GIIPS economies (Greece, Ireland, Italy, Portugal and Spain) would have been cut from nearly 18 percent below trend by the end of 2014 to only 1 percent below trend.

Allowing European nations to pursue independent monetary policy in the face of austerity

\footnotetext{
${ }^{1}$ Belgium, Germany, Estonia, France, Luxembourg, Netherlands, Austria, Slovenia, Slovak Republic, Finland.
} 
shocks helps limit the drop in GDP. Relative to the benchmark model, allowing countries to have independent monetary policy would raise output for the GIIPS economies but would reduce output for the EU10. This is because the nominal exchange rate depreciates in the GIIPS region, stimulating exports and output. In contrast, under the euro, the EU10 already enjoys the export advantage of a relatively weak currency.

Finally, the model also allows us to consider the dynamics of the debt-to-GDP ratio under different conditions. The main rationale for austerity is to reduce debt and bring debt-to-GDP ratios back to historical norms. However, according to our model, reductions in government spending had a sufficiently severe contractionary effect on economic activity that debt-to-GDP ratios in some countries actually increased as a consequence of austerity.

Our research relates to a large and growing body of work on the economic consequences of fiscal austerity and tax and spending multipliers in open economy settings. Alesina, Favero and Giavazzi (2015) and Alesina et al. (2016) examine the economic consequences of planned, multi-year, fiscal adjustments in OECD economies. Their identification strategy borrows from Romer and Romer (2010) by isolating fiscal consolidations motivated by long run budget concerns and excluding cyclical fiscal adjustments. According to their analysis, spendingbased fiscal consolidations entail relatively small economic costs while tax-based consolidations are substantially more costly. Our analysis differs from theirs in several dimensions. While Alesina, Favero and Giavazzi (2015) base their conclusions on data since 1978, our paper focuses exclusively on the post crisis period 2010-2014. This is important because the 20102014 period was characterized by large contractions in government spending, unusually high debt, a preexisting currency union with coordinated monetary policy, interest rates that were essentially at the ZLB, and financial market failures. Another important difference is that we focus on actual changes in spending and taxes rather than preannounced plans for fiscal consolidation. To the extent that governments implemented multi-year fiscal consolidation plans, these would be included in our estimates of fiscal shocks.

The setup of our model is similar to Blanchard, Erceg and Lindé (2016) who use a twocountry DSGE model (based on Erceg and Lindé, 2013) to study how changes in spending by the core economies in Europe affect countries on the periphery. They find sizeable spillover effects when trade flows are large and countries are at the ZLB. We use a multi-country model that reflects relative country size, trade linkages, heterogeneous fiscal policy and actual differences in monetary policy regimes. The multi-country setting more precisely capture cross-country spillovers and produces more realistic counterfactuals. Because trade is widely 
dispersed throughout Europe, cross-country spillover effects are more muted in our multicountry framework relative to standard two-country models.

Martin and Philippon (2016) examine business cycle dynamics in seven euro area countries around the time of the financial crisis. In their model, fiscal consolidations are a consequence of the buildup in public debt prior to the crisis and the associated increase in credit spreads. Our results are similar to the extent that contractions in government spending are associated with large reductions in economic activity. However, while Martin and Philippon (2016) are correct to draw attention to the contractionary effects of debt deleveraging, we find negative effects of fiscal consolidation independent of the level of debt and credit spreads. Indeed, even if we exclude high-debt countries from the analysis, we still find clear and compelling evidence of negative consequences of fiscal austerity in the aftermath of the Great Recession.

\section{The Empirical Relationship between Austerity and Economic Performance}

Table 1 lists the countries in our data set together with each country's relative size, the share of imports in final demand and the country's exchange rate regime as of $2010 .^{2}$ Country size varies from less than one percent of the European aggregate (e.g. Cyprus and Luxembourg) to almost 100 percent (the U.S.). ${ }^{3}$ The import share varies from a low of 13 percent in the U.S. to very high shares in Ireland and Luxembourg (44 percent and 57 percent, respectively). The average import share in our sample of European countries is 32 percent. The model in Section 3 will capture the extent of bilateral trade linkages between country pairs, as well as the overall openness to trade. Most countries in the sample have a fixed exchange rate because they are part of the euro area, or they have pegged their exchange rate to the euro. Nine have floating exchange rates.

\footnotetext{
${ }^{2}$ Our primary data sources are Eurostat and the OECD. The dataset includes all countries in the European Union with the exception of Croatia and Malta (excluded due to data limitations) and with the addition of Norway and Switzerland (outside of the European Union but members of the European Free Trade Association, EFTA). Our sample covers the period 1960 to 2014; it is an unbalanced panel due to limitations in data availability for some countries.

${ }^{3}$ Country size is measured as the country's final demand (in nominal US dollars) relative to the sum of all European countries' final demand, where final demand is GDP less net exports. The European aggregate is the sum of all European countries in our sample. The import share is the share of imports in final demand both averaged over 2005-2010. We construct this share from the OECD Trade in Value Added database.
} 


\subsection{Measuring Austerity}

There are two conceptual issues in studying the impact of fiscal austerity on economic outcomes. One is that a policy can only be said to be austere relative to some benchmark. The second issue is the endogeneity of fiscal policy to the state of the economy - did a cut in government expenditures adversely affect output, or did government expenditures contract along with the decline in output? A commonly adopted approach is to identify periods of austerity as episodes when, for example, the primary balance (the general government balance net of interest payments) decreases by a certain amount. Such data is available from the IMF and the OECD, often reported as a share of "cyclically-adjusted GDP" as a way of correcting for the current stage of the business cycle. This approach partially addresses the issue of defining austerity by picking an arbitrary cut off, but does not address endogeneity. An alternative is the narrative approach pioneered by Romer and Romer (2004). This method relies on a subjective assessment of the historical policy record to identify policy shifts that are motivated by long-run fiscal consolidation rather than the need for short-run temporary fiscal stimulus. The narrative approach addresses the endogeneity problem, though it requires judgment in interpreting policy statements by government officials. The identified policy shifts may also reflect the intent of policymakers and not capture the policies that are ultimately enacted. ${ }^{4}$

A third approach, and the one we adopt here, is to examine forecast errors in government purchases and their relationship with associated forecast errors in economic outcomes. ${ }^{5} \mathrm{We}$ borrow heavily from Blanchard and Leigh (2013) who take a similar approach. However, rather than relying on forecasts generated by the IMF or national governments, we produce our own forecast measures. This gives us the flexibility to consider different methods of detrending and additional explanatory variables. The constructed forecast errors can be interpreted as departures from "normal" fiscal policy reactions to economic fluctuations. If government purchases do not typically increase during economic contractions and this policy reaction continues in the 2010-2014 period, our procedure will categorize that spending path as "not austere." On the other hand, if spending typically increases during recessions but does not do

\footnotetext{
${ }^{4}$ Alesina, Favero and Giavazzi (2015) and Alesina et al. (2016) use the Romer-Romer approach to identify the effect of multi-year fiscal plans on economic activity. Using historical data, they find strong effects of tax changes on economic activity. Our analysis differs in that we focus on the 2010-2014 period which was dominated by reductions in government expenditures.

${ }^{5}$ We also examined austerity in total government outlays, total revenue, and the primary balance. This analysis suggested that, unlike government purchases, changes in tax revenue and the primary balance have limited explanatory power for economic performance. The results using these alternative measures of austerity are included in the Appendix.
} 
so in the aftermath of the crisis, our procedure will categorize that spending path as "austere."

We adopt the following forecast specification for real government purchases:

$$
\begin{aligned}
\ln G_{i, t}= & \ln G_{i, t-1}+g+\gamma\left(\ln \widehat{Y}_{E U, t-1}-\ln Y_{i, t-1}\right) \\
& +\theta^{G}\left(\ln Y_{i, t}-\ln \widehat{Y}_{i, t}\right)+\varepsilon_{i, t}^{G}
\end{aligned}
$$

Here $\ln G_{i, t}$ is the $\log$ of real government purchases in country $i$ at time $t, \ln Y_{i, t}$ is the $\log$ of real Gross Domestic Product for country $i$ at time $t$. The "hat" indicates the predicted value of the variable. This forecast specification accounts for both cross-sectional average growth in GDP (the parameter $g$ ) and convergence dynamics (through the parameter $\gamma$ ) as well as an estimated cyclical relationship (through the parameter $\theta^{G}$ ). This forecast method appeals to basic growth theory as it assumes that all countries are ultimately converging to a common growth rate $g$. Thus, it predicts that growth rates in Central and Eastern European countries are expected to decline as their per capita GDP approaches Western European levels.

To implement this equation we first estimate average GDP growth for twelve euro area economies ${ }^{6}$ for the period 1993-2005 (annual) with an OLS estimate of

$$
\ln Y_{E U, t}=\beta_{E U}+g \cdot t+e_{E U, t} .
$$

The estimated value for $g$ is 0.019 (i.e., 1.9 percent annual growth) with a standard error of 0.0012. To construct the convergence parameter $\gamma$ we then run the regression

$$
\ln Y_{i, t}-\ln Y_{i, t-1}-\hat{g}=\gamma\left(\ln \hat{Y}_{E U, t-1}-\ln \hat{Y}_{i, t-1}\right)+\varepsilon_{i, t}^{\gamma}
$$

using a sample which includes all countries in Central and Eastern Europe ${ }^{7}$ for the same time period. Note, the variable $\ln \widehat{Y}_{E U, t-1}$ is the fitted value from (2.2). Our estimated value for $\gamma$ is 0.023 with a standard error of 0.002 . We then estimate the parameter $\theta^{G}$ by least squares from (2.1) using all available data up to 2005. The fitted value for $\ln \hat{Y}_{i, t-1}$ comes from our forecast of GDP which we discuss in detail below. The estimate of the cyclicality parameter is $\hat{\theta}^{G}=0.38$ with a standard error of 0.06 .

The parameters in the forecast equations are estimated using data prior to the crisis.

\footnotetext{
${ }^{6}$ Belgium, Denmark, Germany, Ireland, Spain, France, Italy, Luxembourg, Austria, Netherlands, Portugal and Finland.

${ }^{7}$ Bulgaria, Czech Republic, Estonia, Greece, Cyprus, Latvia, Lithuania, Hungary, Poland, Romania, Slovenia and the Slovak Republic.
} 
Specifically, we use only data up to 2005:4 to estimate the parameters of the forecasting equations. Our period of interest is after the crisis, 2010-2014. The forecast errors for 2010 through 2014 are the difference between predicted values and the actual values. The predicted values are based on the forecasting parameters as well as information on government purchases up to 2009. So, for the year 2010, we use the actual realizations of $\ln G_{i, 2009}$ and $\ln Y_{i, 2009}$ in (2.1). Starting from $t=2011$, we replace $\ln G_{i, t-1}$ with its predicted value. Thus, for 20102014, our forecasts use data on government purchases up to 2009, but use observed data on GDP. The reason for including actual GDP in the forecast is that we want to limit the endogeneity of government purchases to the current state of the economy.

The out-of-sample residuals can be interpreted as unusually high or low realizations of that variable relative to its predicted values taking current economic conditions into account. Though they are not identified structural shocks from an econometric point of view, we can still ask whether there is a correlation between the forecast errors of government policy and various measures of economic performance. ${ }^{8,9}$

\subsection{Measures of Economic Performance}

We construct measures of economic performance in a similar manner to the forecasting procedure for government purchases. We use the following forecast specification for real GDP, consumption, and investment:

$$
\ln Y_{i, t}=\ln Y_{i, t-1}+g+\gamma\left(\ln \widehat{Y}_{E U, t-1}-\ln Y_{i, t-1}\right)+\varepsilon_{i, t}^{Y}
$$

Equation (2.3) is written for real per capita GDP $(Y)$. As with the forecasts for government purchases, this forecast specification accounts for both average GDP growth (the parameter $g$ ) and convergence dynamics (the parameter $\gamma$ ). The parameters $g$ and $\gamma$ are estimated over the time period 1993 - 2005 just as they were in Section 2.1 and $\ln \widehat{Y}_{E U, t-1}$ is the fitted value from $(2.2) \cdot{ }^{10}$ In addition to providing the forecasts for GDP, consumption, and investment, the

\footnotetext{
${ }^{8}$ The statistical properties of the forecast errors for government purchases as well as forecast errors for several other measures of austerity are reported in the Appendix.

${ }^{9}$ Martin and Philippon (2016) emphasize the relationship between debt and fiscal policy leading up to and following the global financial crisis. Inclusion of lagged debt in the forecasting equation (2.1) yields a small coefficient and has a minor influence on the forecast for government purchases with the exception of Greece. All of our results go through when the GIIPS countries are removed from the sample.

${ }^{10}$ There is a slight difference in the construction of $g$ and $\gamma$ for the performance measures because we use quarterly data for these estimates while we used annual data for the fiscal measures. This difference in the estimates is negligible. We also re-estimate $g$ and $\gamma$ for consumption, and investment because their share in
} 
equation above also provides the variables $\ln \widehat{Y}_{i, t-1}$ used in (2.1). As before, up to $t=2010: 1$, we use actual GDP data for $\ln Y_{i, t-1}$ in $(2.3)$, and replace it by its forecast $\ln \widehat{Y}_{i, t-1}$ thereafter. To construct forecasts for GDP growth, we take the difference in the log-level forecasts. That is, $\Delta \ln \widehat{Y}_{i, t}=\ln \widehat{Y}_{i, t}-\ln \widehat{Y}_{i, t-1}$.

For the remaining performance indicators (inflation, net exports and the nominal exchange rate), we impose a random-walk specification. To reduce the sensitivity to the last observation, for each country we take an average of the variable to be forecast for the two years 2008 and 2009 as the "last observation." That is, for dates $t$ after 2009 our forecast for inflation is ${ }^{11}$

$$
\hat{\pi}_{i, t}=\frac{1}{8} \sum_{s=2008: 1}^{2009: 4} \pi_{i, s}
$$

Figure 2 shows time series plots for government purchases and real GDP for Germany, France, Greece and the United States (figures for the other countries are in the Appendix). The figures show the actual series (the solid line) and the prediction based on our forecasting regressions (the dashed line). The shaded portion of each figure shows the period of our analysis, 2010-2014. In Germany, the difference between the forecast for government purchases and actual government purchases is slight, indicating virtually no austerity, at least relative to the historical pattern of German fiscal policy. In contrast, government purchases in France and Greece are well below forecast. The forecasting equation for the United States picks up the expansion in US fiscal policy in 2008 and 2009, but suggests a significant contraction thereafter. In terms of economic performance (the graphs on the right), France and Greece experience output below forecast. German output was above forecast in 2011 and 2012, with the gap closing in 2013 and 2014. In the United States, the gap between forecasted and actual GDP is very slight.

GDP is likely affected by growth dynamics.

${ }^{11}$ We use "core inflation" (all items less energy and food) as reported by Eurostat. The exchange rate is the nominal effective exchange rate (the trade-weighted sum of bilateral nominal exchange rates). The net export measure is real exports in date $t$ less real imports in date $t$ divided by 2005:1 nominal GDP. We multiply real exports and real imports by their respective deflators for 2005:1, so that, for 2005:1, our measure of net exports equals nominal net exports over nominal GDP. 


\subsection{Austerity and Economic Performance in the Cross Section}

Table 2 reports estimates from cross-sectional OLS regressions of the form

$$
\tilde{X}_{i, 2010-2014}=\alpha_{0}+\alpha \tilde{G}_{i, 2010-2014}+\Gamma \cdot \operatorname{controls}_{i}+\varepsilon_{i}
$$

Here $\tilde{X}_{i, 2010-2014}$ denotes the average forecast error for any of the measures of economic performance, $\frac{1}{20} \sum_{t=2010: 1}^{2014: 4}\left(\ln X_{i, t}-\ln \hat{X}_{i, t}\right)$. For consumption and investment, we express this average forecast error in terms of GDP by pre-multiplying it by the average share of consumption and investment in GDP over the 2000 - 2010 period, $X_{i} / Y_{i}$. Similarly, $\tilde{G}_{i, 2010-2014}$ is the average forecast error for government purchases expressed as a percent of GDP so that the coefficient $\alpha$ can be interpreted as a multiplier. ${ }^{12,13}$ Note that this estimate is based on cross-sectional variation in the data rather than time-series variation.

Table 2 reports estimates of the effects of shortfalls in government purchases on real GDP for eleven different econometric specifications. In addition to the government purchases shortfall, we consider the effects of changes in total revenue, total factor productivity (TFP), and four measures of credit market conditions: the household debt-to-GDP ratio, the government debt-to-GDP ratio, the private credit spread and the government bond spread. We report the negative of the coefficient to convey the effect of "austerity", i.e., a government purchases shortfall, on GDP. The coefficient on government purchases, absent any other variables that could explain the cross sectional variation in GDP, is -2.55 with a standard error of 0.36 . Taken at face value, this suggests that a shortfall in government purchases of one percent of GDP is associated with a decline in real GDP of 2.55 percent relative to forecast.

Columns (2) through (7) show the effects of including additional covariates on the regression results. Total revenue comes in significantly and slightly decreases the coefficient on the shortfall in government purchases. Stronger growth in TFP over 2010-2014 is associated with stronger economic performance. With the exception of the government bond spread, the credit measures (columns (4)-(6)) have essentially no impact on the multiplier. The inclusion of the government bond spreads (measured as the change in post-crisis levels vs. pre-crisis levels), even though not statistically significant, reduces the multiplier to roughly 2. Columns (8)

\footnotetext{
${ }^{12}$ This approach follows Hall (2009) and Barro and Redlick (2009). Ramey and Zubairy (2014) discusses the advantages of directly estimating the multiplier rather than backing it out from an estimated elasticity.

${ }^{13}$ We repeated this analysis for tax revenue and for statutory tax rates. Tax shocks were much smaller than the government purchase shocks and had limited association with economic activity. Thus, we exclude tax shocks from the model though we include controls for tax revenue in the estimates in Table 2.
} 
through (11) each include total revenue and TFP together with each of the credit measures. Depending on the controls, the estimated multiplier is between roughly -2.55 (specification 1) and -1.69 (specification 10). We take specification (11) and the multiplier of -1.98 as our benchmark for assessing the performance of the model in Section 3. This specification has the virtue of producing an estimate roughly in the middle of the range of estimates and includes controls for productivity, taxes and credit market stress.

Table 3 reports results of regressions of other measures of economic performance on shortfalls in government purchases. In each regression, we include all of the control variables from specification (11) of Table 2 though the table reports only the coefficients on government purchases shortfalls. The table also shows the results for subsamples of fixed and floating exchange rates. In particular, we interact the average forecast deviation of government purchases with a dummy for fixed exchange rate countries and report estimates of the corresponding coefficients $\alpha^{f i x}$ and $\alpha^{f l}{ }^{14}$

The results in the table indicate that shortfalls in government purchases are associated with declines in consumption, investment and GDP growth. These estimates are roughly the same across countries with fixed and floating exchange rates. The decrease in investment is noteworthy because many textbook models would predict a crowding-out effect where decreases in government purchases would lead to an increase in investment. Government purchases shortfalls are also associated with lower inflation. Interestingly, this effect is independent of the exchange rate regime although the effect is stronger for fixed exchange rate countries. One possible interpretation of this finding is as evidence for a cross-sectional Phillips Curve relationship similar to the findings in Beraja, Hurst and Ospina (2014), Beraja, Hurst and Ospina (2016) and Nakamura and Steinsson (2014). There is also a strong positive association between net exports and government purchases shortfalls, which, for floating exchange rate countries, is associated with a depreciation of the nominal effective exchange rate.

\section{Model}

Next we develop a multi-country business cycle model of the 29 countries in our data set, plus a rest-of-the-world country. The model will be used to make comparisons with the empirical patterns in Section 2. We will then be able to use the model to perform counterfactual

\footnotetext{
${ }^{14}$ The regression allows for separate intercepts for each exchange rate regime though the coefficients on the control variables are restricted to be the same for all countries.
} 
policy analysis. The model is calibrated to match both the economic size and bilateral trade flows of the 30 countries. The model incorporates many features from modern monetary business cycle models (e.g. Smets and Wouters, 2007; Christiano, Eichenbaum and Evans, 2005), international business cycles models (e.g. Backus, Kehoe and Kydland, 1992, 1994; Chari, Kehoe and McGrattan, 2000; Heathcote and Perri, 2002), and financial accelerator models (e.g. Bernanke, Gertler and Gilchrist, 1999; Brave et al., 2012; Christiano, Motto and Rostagno, 2014). The main ingredients of the model are (i) price rigidity (ii) international trade, (iii) hand-to-mouth consumers, (iv) a net worth channel for business investment and (v) government purchases shocks, monetary policy shocks and spread shocks.

\subsection{Households}

The world economy is populated by $n=1 \ldots N$ countries. All variables in the model are in per capita terms. To convert any variable to a national total, we scale by the population of country $n, \mathbb{N}_{n}$. In each period $t$ the economy experiences one event $s_{t}$ from a potentially infinite set of states. We denote by $s^{t}$ the history of events up to and including date $t$. The probability at date 0 of any particular history $s^{t}$ is given by $\pi\left(s^{t}\right)$.

Every country has a representative household, a single type of intermediate goods producing firm and a single type of final goods producing firm. As in Heathcote and Perri (2002), intermediate goods are tradable across countries, but final goods are nontradable. The households own all of the domestic firms.

We follow Nakamura and Steinsson (2014) who adopt the specification of Greenwood, Hercowitz and Huffman (1988) (GHH hereafter) in assuming that consumption and labor are complements for the household. At date 0 , the expected discounted sum of future period utilities for a household in country $n$ is given by

$$
\sum_{t=0}^{\infty} \sum_{s^{t}} \pi\left(s^{t}\right) \beta^{t} U\left(c_{n}\left(s^{t}\right), L_{n}\left(s^{t}\right)\right)
$$

We set the flow utility function $U(\cdot)$ as

$$
U\left(c_{n}, L_{n}\right)=\frac{1}{1-\frac{1}{\sigma}}\left(c_{n}-\kappa_{n} \frac{L_{n}^{1+\frac{1}{\eta}}}{1+\frac{1}{\eta}}\right)^{1-\frac{1}{\sigma}}
$$

where $\beta<1$ is the subjective time discount factor, $\sigma$ is the intertemporal elasticity of substitu- 
tion for consumption, $\eta$ is the Frisch labor supply elasticity and $\kappa_{n}$ is a country specific weight on the disutility of labor. Households choose state-contingent consumption sequences $c_{n}\left(s^{t}\right)$, labor sequences $L_{n}\left(s^{t}\right)$, next period's capital stock $K_{n}\left(s^{t}\right)$ and current investment $X_{n}\left(s^{t}\right)$ to maximize the expected discounted sum of future period utilities subject to a sequence of budget constraints. Consumption is subject to a time-invariant value-added $\operatorname{tax} \tau_{n}^{c}$.

A key feature of the model is a hand-to-mouth restriction on a fraction $\chi$ of the consumers in the economy. These consumers receive income in proportion to their consumption share of total income and spend the entire amount on current consumption. That is, hand-to-mouth consumption each period is given by $c_{n}^{h t m}\left(s^{t}\right) \equiv \frac{\bar{C}_{n}}{Y_{n}} Y_{n}\left(s^{t}\right)$ where the bars indicate steady state values. ${ }^{15}$ Aggregate consumption is then given by

$$
C_{n}\left(s^{t}\right)=(1-\chi) c_{n}\left(s^{t}\right)+\chi c_{n}^{h t m}\left(s^{t}\right) .
$$

This specification allows us to introduce hand-to-mouth behavior while leaving the other firstorder conditions unchanged. Households in each country own the capital stock in their country. They supply labor to the intermediate goods producing firms and capital to the entrepreneurs. In return, they earn nominal wages net of labor taxes $\left(1-\tau_{n}^{L}\right) W_{n}\left(s^{t}\right) L_{n}\left(s^{t}\right)$ and nominal payments for capital $\mu_{n}\left(s^{t}\right) K_{n}\left(s^{t-1}\right)$. Here $W_{n}\left(s^{t}\right)$ is the state-contingent nominal wage, $\tau_{n}^{L}$ is a constant labor tax rate and $\mu_{n}\left(s^{t}\right)$ is the state-contingent nominal price of capital. ${ }^{16}$ The household also receives lump-sum transfers $\mathbb{T}_{n}\left(s^{t}\right)$. This transfer includes nominal profits from intermediate goods firms and entrepreneurs, $\Pi_{n}^{f}\left(s^{t}\right)+\Pi_{n}^{e}\left(s^{t}\right)$, nominal lump-sum taxes or transfers $T_{n}\left(s^{t}\right)$, profits or losses from the financial sector $\Pi_{n}^{f i n}\left(s^{t}\right)$ and the nominal amount consumed by hand-to-mouth consumers, $P_{n}\left(s^{t}\right) c_{n}^{h t m}\left(s^{t}\right)$ where $P_{n}\left(s^{t}\right)$ is the date $t$ nominal price of the final good. ${ }^{17}$ Thus,

$$
\mathbb{T}_{n}\left(s^{t}\right) \equiv \Pi_{n}^{f}\left(s^{t}\right)+\Pi_{n}^{e}\left(s^{t}\right)+\Pi_{n}^{f i n}\left(s^{t}\right)-T_{n}\left(s^{t}\right)-P_{n}\left(s^{t}\right) c_{n}^{h t m}\left(s^{t}\right)
$$

In addition to direct factor incomes and transfer payments, the household may receive

\footnotetext{
${ }^{15}$ Technically, our specification for the hand-to-mouth consumers assumes that they spend a fixed share of domestic absorption $Y_{n}\left(s^{t}\right)$ rather than a fixed share of nominal national income $p_{n}\left(s^{t}\right) Q_{n}\left(s^{t}\right)$. Quantitatively there is only a small difference between these specifications.

${ }^{16} \mathrm{We}$ assume that households sell capital to entrepreneurs and then subsequently repurchase the undepreciated capital. This assumption is convenient when we introduce financial market imperfections later.

${ }^{17}$ In addition to lending to other countries, households extend domestic loans to financial intermediaries who in turn lend to domestic entrepreneurs at a risky interest rate $\left(1+i_{n, t}\right) F\left(\lambda_{n, t}\right) e^{\epsilon_{n, t}^{F}}$. Profits or losses on these loans are returned to the household as a lump sum transfer. We discuss the loans to the entrepreneurs in greater detail below.
} 
payments from both state-contingent and non-contingent bonds. Let $b_{n}\left(s^{t}, s_{t+1}\right)$ be the quantity of state-contingent bonds purchased by the household in country $n$ after history $s^{t}$. These bonds pay off in units of a reserve currency which we take to be U.S. dollars. Let $a\left(s^{t}, s_{t+1}\right)$ be the nominal price of one unit of the state-contingent bond which pays off in state $s^{t+1}$. Each country has non-contingent nominal bonds that can be traded. Let $S_{n}^{j}\left(s^{t}\right)$ be the number of bonds denominated in country $j$ 's currency and held by the representative agent in country $n$. The gross nominal interest rate for country $n$ 's bonds is $1+i_{n}\left(s^{t}\right)$. The nominal exchange rate to convert country $n$ 's currency into the reserve currency is $E_{n}\left(s^{t}\right)$.

The nominal budget constraints for the representative household in country $n$ are

$$
\begin{aligned}
& P_{n}\left(s^{t}\right)\left[\left(1+\tau_{n}^{c}\right) c_{n}\left(s^{t}\right)+X_{n}\left(s^{t}\right)\right]+(1-\delta) \mu_{n}\left(s^{t}\right) K_{n}\left(s^{t-1}\right)+\sum_{j=1}^{N} \frac{E_{j}\left(s^{t}\right) S_{n}^{j}\left(s^{t}\right)}{E_{n}\left(s^{t}\right)} \\
& +\mathbb{I}_{\text {comp }}\left[\sum_{s^{t+1}} \frac{a\left(s^{t}, s_{t+1}\right) b_{n}\left(s^{t}, s_{t+1}\right)}{E_{n}\left(s^{t}\right)}-\frac{b_{n}\left(s^{t-1}, s_{t}\right)}{E_{n}\left(s^{t}\right)}\right] \\
& =\mu_{n}\left(s^{t}\right) K_{n}\left(s^{t}\right)+\left(1-\tau_{n}^{L}\right) W_{n}\left(s^{t}\right) L_{n}\left(s^{t}\right)+\sum_{j=1}^{N} \frac{E_{j}\left(s^{t}\right)\left(1+i_{j}\left(s^{t-1}\right)\right) S_{n}^{j}\left(s^{t-1}\right)}{E_{n}\left(s^{t}\right)}+\mathbb{T}_{n}\left(s^{t}\right)
\end{aligned}
$$

and the capital accumulation constraints are

$$
K_{n}\left(s^{t}\right)=K_{n}\left(s^{t-1}\right)(1-\delta)+\left[1-f\left(\frac{X_{n}\left(s^{t}\right)}{X_{n}\left(s^{t-1}\right)}\right)\right] X_{n}\left(s^{t}\right)
$$

with $f(1)=f^{\prime}(1)=0$ and $f^{\prime \prime}(1) \geq 0$. As in Christiano, Eichenbaum and Evans (2005), the function $f(\cdot)$ features higher-order adjustment costs on investment if $f^{\prime \prime}(1)>0$. The indicator variable $\mathbb{I}_{\text {comp }}$ takes the value 1 if markets are complete and 0 otherwise. ${ }^{18}$

The first order conditions for an optimum are as follows. The optimizing household's Euler equation for purchases of state contingent bonds $b_{n}\left(s^{t}, s_{t+1}\right)$ requires

$$
a\left(s^{t}, s_{t+1}\right) \frac{U_{1}\left(c_{n}\left(s^{t}\right), L_{n}\left(s^{t}\right)\right)}{E_{n}\left(s^{t}\right) P_{n}\left(s^{t}\right)}=\beta \pi\left(s^{t+1} \mid s^{t}\right) \frac{U_{1}\left(c_{n}\left(s^{t+1}\right), L_{n}\left(s^{t+1}\right)\right)}{E_{n}\left(s^{t+1}\right) P_{n}\left(s^{t+1}\right)}
$$

where $U_{j}(\cdot)$ denotes the derivative of the function $U(\cdot)$ with respect to its $j^{\text {th }}$ argument. There

\footnotetext{
${ }^{18}$ Because models with incomplete markets often have non-stationary equilibria, we impose a small cost of holding claims on other countries. This cost implies that the equilibria is always stationary. For our purposes, we set the cost sufficiently low that its effect on the equilibrium is negligible.
} 
are also Euler equations associated with the uncontingent nominal bonds $S_{n}^{j}\left(s^{t}\right)$. These require

$$
\frac{U_{1}\left(c_{n}\left(s^{t}\right), L_{n}\left(s^{t}\right)\right)}{P_{n}\left(s^{t}\right)} \frac{E_{j}\left(s^{t}\right)}{E_{n}\left(s^{t}\right)}=\beta\left(1+i_{j}\left(s^{t}\right)\right) \sum_{s^{t+1}} \pi\left(s^{t+1} \mid s^{t}\right)\left[\frac{E_{j}\left(s^{t+1}\right)}{E_{n}\left(s^{t+1}\right)} \frac{U_{1}\left(c_{n}\left(s^{t+1}\right), L_{n}\left(s^{t+1}\right)\right)}{P_{n}\left(s^{t+1}\right)}\right]
$$

for all $j=1 \ldots N$. The labor supply condition is

$$
-\frac{U_{2}\left(c_{n}\left(s^{t}\right), L_{n}\left(s^{t}\right)\right)}{U_{1}\left(c_{n}\left(s^{t}\right), L_{n}\left(s^{t}\right)\right)}=\left(\frac{1-\tau_{n}^{L}}{1+\tau_{n}^{c}}\right) \frac{W_{n}\left(s^{t}\right)}{P_{n}\left(s^{t}\right)}
$$

Finally, the optimal choice for investment and capital requires

$$
\begin{aligned}
1= & \frac{\mu_{n}\left(s^{t}\right)}{P_{n}\left(s^{t}\right)}\left\{1-f\left(\frac{X_{n}\left(s^{t}\right)}{X_{n}\left(s^{t-1}\right)}\right)-\frac{X_{n}\left(s^{t}\right)}{X_{n}\left(s^{t-1}\right)} f^{\prime}\left(\frac{X_{n}\left(s^{t}\right)}{X_{n}\left(s^{t-1}\right)}\right)\right\} \\
& +\beta \frac{U_{1}\left(c_{n}\left(s^{t+1}\right), L_{n}\left(s^{t+1}\right)\right)}{U_{1}\left(c_{n}\left(s^{t}\right), L_{n}\left(s^{t}\right)\right)} \frac{\mu_{n}\left(s^{t+1}\right)}{P_{n}\left(s^{t+1}\right)}\left(\frac{X_{n}\left(s^{t+1}\right)}{X_{n}\left(s^{t}\right)}\right)^{2} f^{\prime}\left(\frac{X_{n}\left(s^{t+1}\right)}{X_{n}\left(s^{t}\right)}\right) .
\end{aligned}
$$

\section{$3.2 \quad$ Firms}

There are three groups of firms in the model. First, there are firms that produce the "final good." The final good is used for consumption, investment and government purchases within a country and cannot be traded across countries. The final good producers take intermediate goods as inputs. Second, intermediate goods firms produce country-specific goods which are used in production by the final goods firms. Unlike the final good, the intermediate goods are freely traded across countries. The intermediate goods firms themselves take sub-intermediate goods or varieties as inputs (the domestic producers of the tradable intermediate in country $n$ use only sub-intermediates produced in country $n$ as inputs). The sub-intermediate goods are produced using capital and labor as inputs. Like the final good, neither capital nor labor can be moved across countries. Below, we describe the production chain of these three groups of firms. We begin by describing the production of the traded intermediate goods.

\subsubsection{Tradable Intermediate Goods}

Each country produces a single (country-specific) type of tradable intermediate good. We employ a two-stage production process to allow us to use a Calvo price setting mechanism. In the first stage, monopolistically competitive domestic firms produce differentiated "subintermediate" goods which are used as inputs into the assembly of the tradable intermediate good for country $n$. In the second stage, competitive intermediate goods firms produce the 
tradable intermediate good from a CES combination of the sub-intermediates. These firms then sell the intermediate good on international markets at the nominal price $p_{n, t}$. We describe the production of the intermediate goods in reverse, starting with the second stage.

Second-Stage Producers The second stage producers assemble the tradable intermediate good from the sub-intermediate varieties. The second stage firms are competitive in both the global market for intermediate goods and the market for subintermediate goods in their own country. The second-stage intermediate goods producers solve

$$
\max _{q_{n}\left(\xi, s^{t}\right)}\left\{p_{n}\left(s^{t}\right) Q_{n}\left(s^{t}\right)-\int_{0}^{1} \varphi_{n}\left(\xi, s^{t}\right) q_{n}\left(\xi, s^{t}\right) d \xi\right\}
$$

subject to the CES production function

$$
Q_{n}\left(s^{t}\right)=\left[\int_{0}^{1} q_{n}\left(\xi, s^{t}\right)^{\frac{\psi_{q}-1}{\psi_{q}}} d \xi\right]^{\frac{\psi_{q}}{\psi_{q}-1}}
$$

where the parameter $\psi_{q}>1$. Here $Q_{n}\left(s^{t}\right)$ is the real quantity of country $n$ 's tradable intermediate good produced at time $t$. The variable $\xi$ indexes the continuum of differentiated types of sub-intermediate producers (thus $\xi$ is one of the sub-intermediate types). The parameter $\psi_{q}>1$ governs the degree of substitutability across the sub-intermediate goods. The date $t$ nominal price of each sub-intermediate good is $\varphi_{n}\left(\xi, s^{t}\right)$ and the quantity of each sub-intermediate is $q_{n}\left(\xi, s^{t}\right)$. It is straightforward to show that the demand for each subintermediate has an iso-elastic form

$$
q_{n}\left(\xi, s^{t}\right)=Q_{n}\left(s^{t}\right)\left(\frac{\varphi_{n}\left(\xi, s^{t}\right)}{p_{n}\left(s^{t}\right)}\right)^{-\psi_{q}}
$$

The competitive price of the intermediate $p_{n}\left(s^{t}\right)$ is then a combination of the prices of the sub-intermediates. In particular,

$$
p_{n}\left(s^{t}\right)=\left[\int_{0}^{1} \varphi_{n}\left(\xi, s^{t}\right)^{1-\psi_{q}} d \xi\right]^{\frac{1}{1-\psi_{q}}}
$$

First-Stage Producers The sub-intermediate goods $q_{n}\left(\xi, s^{t}\right)$ which are used to assemble the tradable intermediate good $Q_{n}\left(s^{t}\right)$ are produced in the first stage. The first-stage producers hire workers at the nominal wage $W_{n}\left(s^{t}\right)$ and rent capital at the nominal rental price 
$R_{n}\left(s^{t}\right)$. Unlike the firms in the second stage, the first-stage, sub-intermediate goods firms are monopolistically competitive. They maximize profits taking the demand curve for their product (3.1) as given. These firms have a Cobb-Douglas production function:

$$
q_{n}\left(\xi, s^{t}\right)=Z_{n}\left(s^{t}\right)\left[k_{n}\left(\xi, s^{t}\right)\right]^{\alpha}\left[l_{n}\left(\xi, s^{t}\right)\right]^{1-\alpha} .
$$

Because the first-stage producers are monopolistically competitive, they typically charge a markup for their products. The desired price naturally depends on the demand curve (3.1). Each type of sub-intermediate good producer $\xi$ freely chooses capital and labor each period but there is a chance that their nominal price $\varphi_{n}\left(\xi, s^{t}\right)$ is fixed to some exogenous level. In this case, the first-stage producers choose an input mix to minimize costs taking the date- $t$ price $\varphi_{n}\left(\xi, s^{t}\right)$ as given. Cost minimization implies that

$$
\begin{gathered}
W_{n}\left(s^{t}\right)=M C_{n}\left(s^{t}\right)(1-\alpha) Z_{n}\left(s^{t}\right)\left[k_{n}\left(\xi, s^{t}\right)\right]^{\alpha}\left[l_{n}\left(\xi, s^{t}\right)\right]^{-\alpha} \\
R_{n}\left(s^{t}\right)=M C_{n}\left(s^{t}\right) \alpha Z_{n}\left(s^{t}\right)\left[k_{n}\left(\xi, s^{t}\right)\right]^{\alpha-1}\left[l_{n}\left(\xi, s^{t}\right)\right]^{1-\alpha}
\end{gathered}
$$

where $M C_{n}\left(s^{t}\right)$ is the marginal cost of production. The capital-to-labor ratios are identical across the sub-intermediate firms, in particular

$$
\frac{k_{n}\left(\xi, s^{t}\right)}{l_{n}\left(\xi, s^{t}\right)}=\frac{\alpha}{1-\alpha} \frac{W_{n}\left(s^{t}\right)}{R_{n}\left(s^{t}\right)}=\frac{u_{n}\left(s^{t}\right) K_{n}\left(s^{t-1}\right)}{L_{n}\left(s^{t}\right)}
$$

This implies that (within any country $n$ ) the nominal marginal cost of production is common for all the sub-intermediate goods firms. Nominal marginal costs can be equivalently expressed in terms of the underlying nominal input prices $W_{n}\left(s^{t}\right)$ and $R_{n}\left(s^{t}\right)$

$$
M C_{n}\left(s^{t}\right)=\frac{W_{n}\left(s^{t}\right)^{1-\alpha} R_{n}\left(s^{t}\right)^{\alpha}}{Z_{n}\left(s^{t}\right)}\left(\frac{1}{1-\alpha}\right)^{1-\alpha}\left(\frac{1}{\alpha}\right)^{\alpha} .
$$

Pricing The nominal prices of the sub-intermediate goods are adjusted only infrequently according to the standard Calvo mechanism. In particular, for any firm, there is a probability $\theta$ that the firm cannot change its price that period. When a firm can reset its price it chooses an optimal reset price. Because the production functions have constant returns to scale, and because the input markets are competitive, all firms that can reset their price at time $t$ optimally choose the same reset price $\varphi_{n}^{*}\left(s^{t}\right)$. The reset price is chosen to maximize the 
discounted value of profits. Firms act in the interest of the representative household in their country so they apply the household's stochastic discount factor to all future income streams. The maximization problem of a firm that can reset its price at date $t$ is

$\max _{\varphi_{n}^{*}\left(s^{t}\right)} \sum_{j=0}^{\infty}(\theta \beta)^{j} \sum_{s^{t+j}} \pi\left(s^{t+j} \mid s^{t}\right) \frac{U_{1}\left(c_{n}\left(s^{t+j}\right), L_{n}\left(s^{t+j}\right)\right)}{\left(1+\tau_{n}^{c}\right) P_{n}\left(s^{t+j}\right)}\left(\varphi_{n}^{*}\left(s^{t}\right)-M C_{n}\left(s^{t+j}\right)\right) Q_{n}\left(s^{t+j}\right)\left(\frac{\varphi_{n}^{*}\left(s^{t}\right)}{p_{n}\left(s^{t+j}\right)}\right)^{-\psi_{q}}$

The solution to this optimization problem requires

$\varphi_{n}^{*}\left(s^{t}\right)=\frac{\psi_{q}}{\psi_{q}-1} \frac{\sum_{j=0}^{\infty}(\theta \beta)^{j} \sum_{s^{t+j}} \pi\left(s^{t+j} \mid s^{t}\right) \frac{U_{1}\left(c_{n}\left(s^{t+j}\right), L_{n}\left(s^{t+j}\right)\right)}{P_{n}\left(s^{t+j}\right)} p_{n}\left(s^{t+j}\right)^{\psi_{q}} M C_{n}\left(s^{t+j}\right) Q_{n}\left(s^{t+j}\right)}{\sum_{j=0}^{\infty}(\theta \beta)^{j} \sum_{s^{t+j}} \pi\left(s^{t+j} \mid s^{t}\right) \frac{U_{1}\left(c_{n}\left(s^{t+j}\right), L_{n}\left(s^{t+j}\right)\right)}{P_{n}\left(s^{t+j}\right)} p_{n}\left(s^{t+j}\right)^{\psi_{q}} Q_{n}\left(s^{t+j}\right)}$.

Because the sub-intermediate goods firms adjust their prices infrequently, the nominal price of the tradable intermediate goods is sticky. In particular, using (3.2), the nominal price of the tradable intermediate good evolves according to

$$
p_{n}\left(s^{t}\right)=\left[\theta p_{n}\left(s^{t-1}\right)^{1-\psi_{q}}+(1-\theta) \varphi_{n}^{*}\left(s^{t}\right)^{1-\psi_{q}}\right]^{\frac{1}{1-\psi_{q}}} .
$$

Our specification of price setting entails firms setting prices in their own currency. As a result, when exchange rates move, the implied import price moves automatically (there is complete pass-through). This is somewhat at odds with the data, which suggest that many exporting firms fix prices in the currency of the country to which they are exporting. ${ }^{19}$

\subsubsection{Nontradable Final Goods}

The final goods are assembled from a (country-specific) CES combination of tradable intermediates produced by the various countries in the model. The final goods firms are competitive in both the global input markets and the final goods market. The final goods producers solve

$$
\max _{y_{n}^{j}\left(s^{t}\right)}\left\{P_{n}\left(s^{t}\right) Y_{n}\left(s^{t}\right)-\sum_{j=1}^{N} \frac{E_{j}\left(s^{t}\right)}{E_{n}\left(s^{t}\right)} p_{j}\left(s^{t}\right) y_{n}^{j}\left(s^{t}\right)\right\}
$$

\footnotetext{
${ }^{19}$ See Gopinath and Itskhoki (2011) and Burstein and Gopinath (2014) for a full treatment of pass-through, price rigidity and exchange rate movements.
} 
subject to the CES production function

$$
Y_{n}\left(s^{t}\right)=\left(\sum_{j=1}^{N} \omega_{n, j}^{\frac{1}{\psi_{y}}} y_{n}^{j}\left(s^{t}\right)^{\frac{\psi_{y}-1}{\psi_{y}}}\right)^{\frac{\psi_{y}}{\psi_{y}-1}}
$$

Here, $y_{n}^{j}\left(s^{t}\right)$ is the amount of country- $j$ intermediate good used in production by country $n$ at time $t$. The parameter $\psi_{y}$ governs the degree of substitutability across the tradable

intermediate goods and the preference weights satisfy $\omega_{n, j} \geq 0$ with $\sum_{j=1}^{N} \omega_{n, j}=1$ for each country $n$. Notice that the weights $\omega_{n, j}$ are country-specific so each country $n$ requires a different mix of the various country-specific intermediate goods as inputs. We later calibrate the $\omega_{n, j}$ parameters to match data on bilateral import shares.

Demand for country-specific intermediate goods is isoelastic:

$$
y_{n}^{j}\left(s^{t}\right)=Y_{n}\left(s^{t}\right) \omega_{n, j}\left[\frac{E_{j}\left(s^{t}\right)}{E_{n}\left(s^{t}\right)} \frac{p_{j}\left(s^{t}\right)}{P_{n}\left(s^{t}\right)}\right]^{-\psi_{y}}
$$

The implied nominal price of the final good is

$$
P_{n}\left(s^{t}\right)=\left(\sum_{j=1}^{N} \omega_{n, j}\left[\frac{E_{j}\left(s^{t}\right)}{E_{n}\left(s^{t}\right)} p_{j}\left(s^{t}\right)\right]^{1-\psi_{y}}\right)^{\frac{1}{1-\psi_{y}}}
$$

Unlike the intermediate goods, the final good cannot be traded and must be used for either investment, consumption or government purchases in the period in which it is produced. Because the final goods firms have constant returns to scale production functions and behave competitively profits are zero in equilibrium.

\subsection{Financial Market Imperfections and the Supply of Capital}

The model incorporates a financial accelerator mechanism similar to Carlstrom and Fuerst (1997) and Bernanke, Gertler and Gilchrist (1999). Entrepreneurs buy capital goods from households using a mix of internal and external funds (borrowing). The entrepreneurs rent out the purchased capital to the first-stage sub-intermediate goods producers in their own country and then sell it back to the household the following period. The interest rate that entrepreneurs face for borrowed funds is a function of their financial leverage ratio. As a consequence, fluctuations in net worth cause changes in the effective rate of return on capital 
and thus directly affect real economic activity. ${ }^{20}$

Formally, at the end of period $t$, entrepreneurs purchase capital $K_{n}\left(s^{t}\right)$ from the households at the nominal price $\mu_{n}\left(s^{t}\right)$ per unit. Entrepreneurs finance these purchases with their own internal funds (net worth) and intermediated borrowing. Let end-of-period nominal net worth be $N W_{n}\left(s^{t}\right)$, denominated in country $n$ 's currency. Then, to purchase capital, the entrepreneur borrows $B_{n}\left(s^{t}\right)=\mu_{n}\left(s^{t}\right) K_{n}\left(s^{t}\right)-N W_{n}\left(s^{t}\right)$ units from the households in their country. The nominal interest rate on business loans equals the nominal interest rate on safe bonds times an external finance premium $F\left(\lambda_{n}\left(s^{t}\right)\right)$ with $F^{\prime}$ and $F^{\prime \prime}>0$. Here, $\lambda_{n}\left(s^{t}\right)=\frac{\mu_{n}\left(s^{t}\right) K_{n}\left(s^{t}\right)}{N W_{n}\left(s^{t}\right)}$ is the leverage ratio. ${ }^{21}$ The interest rate is then $\left(1+i_{n}\left(s^{t}\right)\right) F\left(\lambda_{n}\left(s^{t}\right)\right) e^{\epsilon_{n}^{F}\left(s^{t}\right)}$, where $\epsilon_{n}^{F}\left(s^{t}\right)$ is a shock to the interest rate spread. The function $F(\cdot)$ implies that entrepreneurs who are more highly leveraged pay a higher interest rate.

At the beginning of period $t+1$, entrepreneurs earn a utilization-adjusted rental price of capital net of capital taxes $\left(1-\tau_{n}^{K}\right) u_{n}\left(s^{t+1}\right) R_{n}\left(s^{t+1}\right)$ and then sell the undepreciated capital back to the households at the capital price $\mu_{n}\left(s^{t+1}\right)$. Depreciation costs are tax deductible. Varying the utilization of capital requires $K_{n}\left(s^{t}\right) a\left(u_{n}\left(s^{t+1}\right)\right)$ units of the final good. Each period, a fraction $\left(1-\gamma_{n}\right)$ of the entrepreneurs' net worth is transferred to the households. ${ }^{22}$

Each period, entrepreneurs choose $K_{n}\left(s^{t+1}\right)$ and utilization $u_{n}\left(s^{t+1}\right)$ to maximize expected net worth $N W_{n}\left(s^{t+1}\right)$. Net worth evolves over time according to

$$
\begin{aligned}
\frac{N W_{n}\left(s^{t+1}\right)}{\gamma_{n}}= & K_{n}\left(s^{t}\right)\left[\left(1-\tau_{n}^{K}\right) u_{n}\left(s^{t+1}\right) R_{n}\left(s^{t+1}\right)+\mu_{n}\left(s^{t+1}\right)\left(1-\delta\left(1-\tau_{n}^{K}\right)\right)-P\left(s^{t+1}\right) a\left(u_{n}\left(s^{t+1}\right)\right)\right] \\
& -\left(1+i_{n}\left(s^{t}\right)\right) F\left(\lambda_{n}\left(s^{t}\right)\right) e^{\epsilon_{n}^{F}\left(s^{t}\right)} B_{n}\left(s^{t}\right)
\end{aligned}
$$

We assume that the entrepreneurs can set utilization freely depending on the date $t$ realization of the state. The utilization choice requires the first order condition

$$
\left(1-\tau_{n}^{K}\right) R_{n}\left(s^{t}\right)=P_{n}\left(s^{t}\right) a^{\prime}\left(u_{n}\left(s^{t}\right)\right) .
$$

Following Christiano, Eichenbaum and Evans (2005) we assume that the utilization cost function is $a(u)=\frac{\bar{R}}{P}[\exp \{h(u-1)\}-1] \frac{1}{h}$ where the curvature parameter $h$ governs how costly it is to increase or decrease utilization from its steady state value of $u=1$. Note that in

\footnotetext{
${ }^{20}$ See Brave et al. (2012) for the same approach.

${ }^{21}$ We assume that $F(1)=1$. Technically, we also assume that for any $\lambda<1, F(\lambda)=1$ so there is no interest rate premium or discount for an entrepreneur who chooses to have positive net saving. Since the return on capital exceeds the safe rate in equilibrium, all entrepreneurs are net borrowers.

${ }^{22}$ We set $\gamma_{n}=\frac{\beta}{F_{n}}$ so that net worth is constant in a stationary equilibrium.
} 
steady state $a(u)=0$.

The first order condition for the choice of $K_{n}\left(s^{t}\right)$ requires

$$
\begin{aligned}
& \mu_{n}\left(s^{t+1}\right)\left(1+i_{n}\left(s^{t}\right)\right) F\left(\lambda_{n}\left(s^{t}\right)\right) e^{\epsilon_{n}^{F}\left(s^{t}\right)} \\
= & \sum_{s^{t+1}} \pi\left(s^{t+1} \mid s_{t}\right)\left[\left(1-\tau_{n}^{K}\right) u_{n}\left(s^{t+1}\right) R_{n}\left(s^{t+1}\right)+\mu_{n}\left(s^{t+1}\right)\left(1-\delta\left(1-\tau_{n}^{K}\right)\right)-P\left(s^{t+1}\right) a\left(u_{n}\left(s^{t+1}\right)\right)\right] .
\end{aligned}
$$

As is standard in financial accelerator models, the external finance premium $F\left(\lambda_{n}\left(s^{t}\right)\right)$ drives a wedge between the nominal interest rate on bonds and the expected nominal return on capital. Notice that if $F\left(\lambda_{n}\left(s^{t}\right)\right)=1$ then we obtain the standard efficient outcome in which the market price of capital is the discounted stream of rental prices.

\subsection{Government Policy}

The model includes both fiscal and monetary policy variables. We assume that government purchases are exogenous and financed by lump sum taxes on the representative households. Consumption, labor and capital tax rates are kept constant. Government purchases in country $n$ are governed by an auto-regressive process

$$
G_{n}\left(s^{t}\right)=\left(1-\rho_{G}\right) \bar{G}_{n}+\rho_{G} G_{n}\left(s^{t-1}\right)+\varepsilon_{n}^{G}\left(s^{t}\right)
$$

where $\bar{G}_{n}$ indicates the steady-state ratio of government purchases to GDP.

Monetary policy is conducted through a Taylor Rule which stipulates that in each country, a monetary authority conducts open market operations in its own currency to target the nominal interest rate. The Taylor Rule we use has the form

$$
i_{n}\left(s^{t}\right)=\bar{\imath}_{n}+\phi_{i} i_{n}\left(s^{t-1}\right)+\left(1-\phi_{i}\right)\left(\phi_{G D P} G D P_{n}\left(s^{t}\right)+\phi_{\pi} \pi_{n}\left(s^{t}\right)\right)+\varepsilon_{n}^{i}\left(s^{t}\right)
$$

For simplicity we assume that the reaction parameters $\phi_{G D P}, \phi_{\pi}$ and $\phi_{i}$ are common across

countries. In all of our numerical exercises, we require that $\frac{\phi_{\pi}}{1-\phi_{i}}>1$ for local determinacy of the equilibrium (see e.g., Woodford and Walsh (2005)).

Countries in the euro area have a fixed nominal exchange rate for every country in the union and a common nominal interest rate. Monetary policy for the countries within the euro area is set by a single monetary authority (the ECB) that has a Taylor Rule similar to (3.5) with the exception that it reacts to the weighted average of innovations in GDP and inflation 
for the countries in the union. The weights are proportional to GDP relative to the total GDP in the euro area.

\subsection{Aggregation and Market Clearing}

For each country $n$, aggregate production of the tradable intermediate goods is (up to a first-order approximation ${ }^{23}$ ) given by

$$
Q_{n}\left(s^{t}\right)=Z_{n}\left(s^{t}\right)\left(u_{n}\left(s^{t}\right) K_{n}\left(s^{t-1}\right)\right)^{\alpha} L_{n}\left(s^{t}\right)^{1-\alpha} .
$$

Final goods production is given by (3.4) and, since the final good is nontradable, the market clearing condition for the final good is

$$
Y_{n}\left(s^{t}\right)=C_{n}\left(s^{t}\right)+X_{n}\left(s^{t}\right)+G_{n}\left(s^{t}\right)+a\left(u_{n}\left(s^{t}\right)\right) K_{n}\left(s^{t-1}\right) .
$$

The market clearing for the intermediate goods produced by country $n$ is

$$
Q_{n}\left(s^{t}\right)=\sum_{j=1}^{N} \frac{\mathbb{N}_{j}}{\mathbb{N}_{n}} y_{j}^{n}\left(s^{t}\right)
$$

Finally, the bond market clearing conditions require

$$
\sum_{n=1}^{N} \mathbb{N}_{n} S_{n}^{j}\left(s^{t}\right)=\sum_{n=1}^{N} \mathbb{N}_{n} b_{n}\left(s^{t}, s_{t+1}\right)=0 \quad \forall j, s_{t+1}
$$

Since no final goods are traded, net exports are comprised entirely of intermediate goods. For each country $n$, define nominal net exports as

$$
N X_{n}\left(s^{t}\right)=p_{n}\left(s^{t}\right) Q_{n}\left(s^{t}\right)-\sum_{j=1}^{n} \frac{E_{j}\left(s^{t}\right)}{E_{n}\left(s^{t}\right)} p_{j}\left(s^{t}\right) y_{n}^{j}\left(s^{t}\right)=p_{n}\left(s^{t}\right) Q_{n}\left(s^{t}\right)-P_{n}\left(s^{t}\right) Y_{n}\left(s^{t}\right)
$$

where the second equality follows from the zero profit condition for the final goods producers. We can use this expression to write nominal GDP as

$$
N G D P_{n}\left(s^{t}\right)=p_{n}\left(s^{t}\right) Q_{n}\left(s^{t}\right)=N X_{n}\left(s^{t}\right)+P_{n}\left(s^{t}\right)\left[C_{n}\left(s^{t}\right)+X_{n}\left(s^{t}\right)+G_{n}\left(s^{t}\right)\right]
$$

\footnotetext{
${ }^{23}$ As is well known in the sticky price literature, actual output includes losses associated with equilibrium price dispersion. In a neighborhood of the steady state, these losses are zero to a first order approximation. Since our solution technique is only accurate to first order, these terms drop out.
} 
Real GDP is $R G D P_{n}\left(s^{t}\right)=p_{n} Q_{n}\left(s^{t}\right)$ (this is the real GDP calculation associated with a fixed price deflator in which the base year prices are chosen as corresponding to the steady state).

\subsection{Steady state}

We solve the model in a neighborhood of a non-stochastic steady state with zero inflation. Because inflation is zero, the Euler equations associated with the uncontingent nominal bonds imply that the nominal interest rate is $1+\bar{\imath}_{n}=\frac{1}{\beta}$ for all $n$. We use the notation $\bar{X}_{n}$ to denote the steady state value of the variable $X$ for country $n$. In the steady state, the nominal price of capital and the nominal price of the final consumption good are equal. The entrepreneurs' optimal choice for capital implies that

$$
\frac{1}{\beta} \bar{F}_{n}=\left(1-\tau_{n}^{K}\right) \frac{\bar{R}_{n}}{\bar{P}_{n}}+\left(1-\delta\left(1-\tau_{n}^{K}\right)\right),
$$

where we have defined the steady state interest rate spreads $\bar{F}_{n} \equiv F_{n}\left(\bar{\lambda}_{n}\right)$. Below we calibrate these spreads to match their observable counterparts. Once we have calibrated $\bar{F}_{n}$, the equation above determines the real rental price of capital $\bar{R}_{n} / \bar{P}_{n}$ in each country. The utilization cost function $a(u)$ is chosen to ensure that $\bar{u}_{n}=1$ and $a\left(\bar{u}_{n}\right)=0$. With zero inflation, the price of intermediates is a constant markup over nominal marginal cost, $\bar{p}_{n}=\frac{\psi_{q}}{\psi_{q}-1} \overline{M C}_{n}$.

We choose parameters to ensure that all real exchange rates $\bar{e}_{j, n} \equiv \frac{\bar{E}_{j}}{\bar{E}_{n}} \frac{\bar{p}_{j}}{\bar{p}_{n}}$ are 1 in steady state. With $\bar{e}_{j, n}=1$ for all $j, n$ it is straightforward to show that the price of the final consumption good and the price of the tradeable intermediate good are equal, $\bar{P}_{n}=\bar{p}_{n}$. Moreover, the bilateral import ratios will satisfy $\frac{\bar{y}_{n}^{j}}{\bar{Y}_{n}}=\omega_{n, j}$, which we will use to calibrate $\omega_{n, j}$. In addition to matching the import ratios, we also calibrate the model to match the observed relative country sizes, $\frac{\mathbb{N}_{j} \bar{Y}_{j}}{\mathbb{N}_{n} \bar{Y}_{n}}$, which ensures that we match the shares of net exports relative to domestic absorbtion $\overline{N X}_{n} / \bar{Y}_{n}$ where $\overline{N X}_{n}=\bar{Q}_{n}-\bar{Y}_{n}$. Finally, we also calibrate our model to match the observed shares of government purchases.

\subsection{Calibration}

Our benchmark calibration is summarized in Table 4.

Preferences We set the subjective time discount factor $\beta$ to imply a long run real annual interest rate of four percent. We set the intertemporal elasticity of substitution $\sigma$ to 0.50 
and the Frisch elasticity of labor supply $\eta$ to 1 . These values are comparable to findings in the microeconomic literature on preference parameters (e.g. Barsky et al., 1997) and fairly standard in the macroeconomic literature (e.g. Nakamura and Steinsson, 2014; Hall, 2009). We set the share of hand-to-mouth consumers to $\chi=0.5$. This is the value proposed by the original study by Campbell and Mankiw (1989) and is consistent with the calibration in Martin and Philippon (2016).

Trade and Country Size The preference parameters $\omega_{n, j}$ are calibrated to the share of imports $y_{n}^{j}$ in the production of the final good, $Y_{n}$, in the data. Standard import data cannot be used for this purpose because it is measured in gross terms, wheras our model requires data in value added terms. We therefore use data from the OECD on trade in value added (TiVA). The dataset is derived from input-output tables, which themselves are based on national account data. The definition of imports and exports in TiVA correspond to those used in national account data and therefore captures trade in both goods and services. The data series FD_VA ('Value added content of final demand') has information on the value added content (in US dollars) of final demand by source country for all country pairs in our data sample. We directly use these values for $y_{n}^{j}$ and the implied final demand value for $Y_{n}$ to calculate $\omega_{n, j}$. TiVA also has data for a 'rest of the world' aggregate. We lump together that data and data for countries that are not in our sample to construct the preference parameters $\omega_{R o W, j}$ for the rest of the world in our sample. TiVA is available for 1995, 2000, 2005, and 2008 through 2011. We take an average of 2005 and 2010 to calibrate $\omega_{n, j}$. Similarly, we choose the relative country sizes to match relative final demand observed in the TiVA tables.

The trade elasticity $\psi_{y}$ is set to 0.5 . This is comparable to parameter values used in international business cycle models with trade. In their original paper, Heathcote and Perri (2002) estimated $\psi_{y}=0.90$. Using firm-level data, Cravino (2014) and Proebsting (2015) find elasticities close to $1.5 .^{24}$ We consider higher trade elasticities in the sensitivity analysis below.

Technology The capital share parameter $\alpha$ is set to 0.38, as in Trabandt and Uhlig (2011) who match data for 14 European countries and the US. The quarterly depreciation rate is set to $2.8 \%$ to match the share of private investment in final demand, $X_{n} / Y_{n}$, whose average

\footnotetext{
${ }^{24}$ The literature on international trade outside of business cycle analysis typically adopts higher elasticities. For instance Broda, Greenfield and Weinstein (2006) find a long-run trade elasticity of 6.8.
} 
value was $19.7 \%$ across all countries in our sample for the years $2000-2010$.

The form of the investment adjustment cost $f(\cdot)$ implies a relationship between investment growth and Tobin's Q. In particular, if $v_{n, t}$ is the Lagrange multiplier in the capital accumulation constraint then Tobin's Q can be defined as $\mathbb{Q}_{n}\left(s^{t}\right)=v_{n}\left(s^{t}\right) / U_{1, n}\left(s^{t}\right)$. It is straightforward to show that the change in investment growth over time obeys the equation

$$
\left[\widetilde{X}_{n}\left(s^{t}\right)-\widetilde{X}_{n}\left(s^{t-1}\right)\right]=\frac{1}{\vartheta} \widetilde{\mathbb{Q}}_{n}\left(s^{t}\right)+\beta\left[\widetilde{X}_{n}\left(s^{t+1}\right)-\widetilde{X}_{n, t}\right]
$$

where $\tilde{X}$ denotes the percent deviation of $X$ from its steady state value. Thus the parameter $\vartheta$ is similar to a traditional inverse $Q$-elasticity. We adopt the value $\vartheta=2.48$ from Christiano, Eichenbaum and Evans (2005) which implies that a one percent increase in $Q$ causes investment to increase by roughly 0.4 percent.

For the utilization cost function $a(u)=\frac{\bar{R}}{P}[\exp \{h(u-1)\}-1] \frac{1}{h}$, the elasticity of utilization with respect to the real rental price of capital is governed by the parameter $h=\frac{a^{\prime \prime}(1)}{a^{\prime}(1)}$. We follow Del Negro et al. (2013) by setting $h=0.286$. This implies that a one percent increase in the real rental price $R_{n} / P_{n}$ causes an increase in the capital utilization rate of 0.286 percent.

Price Rigidity We calibrate the Calvo price setting hazard to roughly match observed frequencies of price adjustment in the micro data. Nakamura and Steinsson (2008) report that prices change roughly once every 8 to 11 months; Klenow and Kryvtsov (2008) report that prices change roughly once every 4 to 7 months. Evidence on price adjustment in Europe suggests somewhat slower adjustment. Alvarez et al. (2006) find that the average duration of prices is 13 months (for a quarterly model this corresponds to $\theta=0.77$ ). Our baseline calibration takes $\theta=0.80$. This is somewhat higher than the empirical findings for U.S. price adjustment. Our main reason for adopting this calibration is to match the data indicating slightly more sluggish price adjustment in European countries compared to the U.S. ${ }^{25}$

Financial Market Imperfections The steady state external finance premia, $F_{n}\left(\bar{\lambda}_{n}\right)$, are calculated as the average spread between lending rates (to non-financial corporations) and central bank interest rates. For every country, we calculate an average for 2005. The data source for the spread data is the ECB for euro area countries, the Global Financial Database and national central banks for the remaining countries. See the Data Appendix for more

\footnotetext{
${ }^{25}$ For purposes of comparison, Christiano, Eichenbaum and Evans (2005) use $\theta=0.6$, Del Negro et al. (2013) have $\theta=0.88$ and Brave et al. (2012) have $\theta=0.97$.
} 
details on the data sources.

For the two remaining parameters we adopt the calibration from Brave et al. (2012). The elasticity of the external finance premium with respect to leverage $F_{\epsilon}$ is 0.20 and the quarterly persistence of the shocks to the external finance premium is set to 0.99 .

Fiscal and Monetary Policy For each country, we set the steady state ratio of government purchases to GDP, $\bar{G}_{n}$, to match the average ratio from 2000 - 2010 in the data provided. The persistence of the government purchase shock is set to 0.93 as in Del Negro et al. (2013). We choose our Taylor rule parameters to be $\phi_{\pi}=1.5, \phi_{G D P}=0.5$ and $\phi_{i}=0.75$.

Tax Rates We use implicit tax rates to calibrate the values for $\tau_{n}^{C}, \tau_{n}^{L}$ and $\tau_{n}^{K}$. Calculation of tax rates for consumption, labor and capital builds on Mendoza, Razin and Tesar (1994) and Eurostat (2014). The principal idea is to classify tax revenue by economic function using data from the National Tax Lists and then approximate the base with data from the national sector accounts. Compared to statutory tax rates, the advantages of these rates are that they take into account the net effect of existing rules regarding exemptions and deductions, and also incorporate social security contributions in labor taxes. We use the average over 2000 through 2009. The Appendix includes a list of all countries and steady-state implicit tax rates.

\section{Model and Data Comparison}

We next simulate the calibrated model's reaction to shocks and compare the simulated data to the actual data. Our approach is to treat the austerity forecast deviations calculated in Section 2 as structural shocks. In addition to the austerity shocks, we also include shocks to monetary policy and shocks to financial markets. Including other shocks is important because it is likely that some of the observed differences in economic performance can be traced to shocks other than austerity.

\subsection{Forcing Variables}

Austerity Shocks Government purchase shocks are based on our forecast errors from equation (2.1). To convert the annual forecast errors to a quarterly series to feed into the model we interpolate them using the Chow-Lin method (Chow and Lin, 1971). 
Monetary Policy Shocks To measure monetary policy shocks we estimate a generalized Taylor rule of the form suggested by Clarida, Gali and Gertler (1997):

$$
i_{n, t}=\rho^{i} i_{t-1}+\left(1-\rho^{i}\right)\left[\pi_{n, t}+r_{n}+\phi_{\pi}\left(\pi_{n, t}-\pi_{n}^{*}\right)+\phi_{G D P}\left(\ln G D P_{n, t}-\ln \overline{G D P}_{n, t}\right)\right]+\varepsilon_{n, t}^{i}
$$

where $i_{n, t}$ is the nominal interest rate, $r_{n}$ is the long-run interest rate, $\pi_{n, t}$ is inflation, $\pi_{n}^{*}$ is the inflation target, $\ln G D P_{n, t}-\ln \overline{G D P}_{n, t}$ is the percent deviations of real GDP from its trend, and $\varepsilon_{n, t}^{i}$ is a structural shock. Inflation is measured using the GDP deflator. The interest rate and the inflation rate are measured in annual percent. We impose a value for $\rho^{i}=0.79$ (see Clarida, Gali and Gertler, 1997) and estimate $\phi_{\pi}$ and $\phi_{G D P}$ for the U.S. over the period 1980:1 - 2005:4. This estimation implicitly assumes that the U.S. has been adhering to a fairly stable monetary rule since the early 1980's.

We then impose the estimated coefficients $\phi_{\pi}, \phi_{G D P}$ and the constrained coefficient $\rho^{i}$ for each of the countries in Europe that have an independent monetary policy. We do not estimate separate Taylor rules for each central bank primarily because of data limitations. For the euro area, we assume that the ECB reacts to the weighted average of inflation and output over all countries in the euro. With these coefficients we then estimate country-specific intercepts (corresponding to the parameters $r_{n}-\phi_{\pi} \pi_{n}^{*}$ in the Taylor rule). We can then recover the monetary policy shocks for each country $n$ as $\hat{\varepsilon}_{n, t}^{i}=i_{n, t}-\hat{\imath}_{n, t}$.

Financial Shocks We take our measure of financial shocks from data on spreads between lending rates and central bank interest rates. For the U.S., data on lending rates comes from the Federal Reserve Survey of Terms of Business Lending. For European countries, we use a dataset provided by the ECB, which we supplement with data from national central banks and the Global Financial Database.

\subsection{Benchmark Model Performance}

We feed the estimated structural shocks for the 2005-2014 period into the model and compare the simulated data with actual data. Throughout, we treat the simulated data (in terms of detrending, scaling and definitions of variables, etc.) in the same way as we treat the empirical data. The benchmark model includes all three structural shocks (austerity shocks, monetary policy shocks and financial shocks) and the baseline calibration given in Table 4.

Table 3 shows a comparison of the cross-sectional multipliers generated by the model and 
the data. The first three columns of the table reproduce the empirical coefficients from Table 2 , broken down into the total sample, the sample of fixed exchange rate countries and the sample of floating exchange rate countries. The corresponding coefficients from the simulated data of the benchmark model are in the last three columns. Several points are worth emphasizing. First, the estimated coefficients from the model are consistent with the estimates from the data in terms of magnitude and sign. Empirically, the government purchases multiplier is 1.98; the corresponding multiplier in the model is 1.95. The response of inflation to government purchases is 0.41 in the data and 0.26 in the model (that is, a shortfall in spending is associated with deflation). The inflation response is somewhat greater for fixed exchange rate countries and weaker for floating exchange rate countries in both the data and the model.

The model does a better job of explaining consumption than investment. While the signs of the responses of consumption and investment are consistent across the model and the data, the magnitudes in the model fall short of the empirical estimates. The hand-to-mouth restriction is critical for generating the large drop in consumption, while the financial shocks are not as successful in generating a sufficiently negative reduction in investment.

In both the model and the data, austerity shocks generate a positive response of net exports. The decrease in government purchases results in a drop in demand for the home good. The decline in demand causes firms to reduce their demand for labor, putting downward pressure on wages and employment. This drop in income causes hand-to-mouth consumers to reduce consumption one-for-one with the drop in GDP. Overall, and despite the positive wealth effect that stimulates consumption of unconstrained households, demand for intermediate goods falls more than supply. Note also that GHH preferences accentuate this effect. Since consumption and labor are complements, households reduce their consumption as they work less, which further stifles demand.

Figures 3a - 3c compare scatterplots of actual data (the left panels) with scatterplots of simulated data (the right panels). Note, the plot of the actual data conditions on the full set of control variables (i.e., specification 11 in Table 2$)$. That is, we plot $\left(\tilde{G}_{n}, \tilde{X}_{n}-\hat{\Gamma} \cdot \operatorname{controls}_{n}\right)$. In each panel, the austerity shocks (i.e., forecast errors) are on the horizontal axis. The units of both axes are log points times 100. The panels show the regression lines for countries with fixed exchange rates (solid dots) and the floating exchange rates (open dots).

The scatterplots reveal several differences between the actual data and the simulated data. First, and most importantly, the actual data has substantially more noise than the simulated data. This is not surprising since the model includes only a limited number of shocks. Second, 
the inflation data exhibits substantially more variation across countries within the euro area than the model permits. In the model, even though there are sharp differences in government purchases across countries, there is a strong tendency for countries in the currency union to have inflation rates that are nearly the same. On the other hand, the model displays substantial differences in inflation for countries that are not in the euro area, while in the data, inflation for these countries does not differ radically from inflation in the euro area. This may be due to the fact that even though the non-euro countries technically have floating exchange rates and independent monetary policy, the monetary authorities in these countries do not depart much from the policies enacted by the ECB.

To get a better sense of the relative importance of the different shocks, Table 5 reports the cross-sectional multipliers for GDP, inflation and net exports for different combinations of the forcing variables. The first column reports the cross-sectional multiplier estimated in the data and the second column reports the corresponding multipliers for the benchmark model. Columns 3 - 5 show what happens as we remove the credit shocks (column 3 ), the money shocks (column 4) or remove both credit and money leaving the government shock by itself (column 5). This exercise makes clear that the negative relationship between austerity and economic performance in the model is driven primarily by government purchases shocks. When only government purchases shocks are fed into the model, the coefficient on GDP is 1.79, compared to 1.95 in the benchmark model. Because monetary policy was generally contractionary and credit conditions were tight, the other shocks reinforce the impact of austerity. The last two rows of the table report the correlation and the standard deviation of simulated GDP relative to actual GDP. The simulated GDP is always highly correlated with observed GDP even as the other shocks are removed. The correlations and the relative standard deviations indicate that austerity accounts for most of the cross-sectional variation in the data.

The one statistic that does depend heavily on shocks other than austerity is the crosssectional response of inflation in countries with floating exchange rates. For these countries, the coefficient on inflation is -0.18 in the data (indicating a decrease in inflation following a contraction in government purchases) but is 0.32 in the model with only austerity shocks. To understand the dynamics of inflation, consider a decline in government purchases in a closed-economy New Keynesian model. Under fairly standard parameter values, the fall in government purchases reduces labor demand by more than the fall in labor supply, and therefore wages fall. The decline in government purchases is thus associated with falling costs and is deflationary. In our open economy setting, however, reductions in government purchases 
are associated with inflation for countries with floating exchange rates due to a depreciation of the currency. The currency depreciation raises the price of imports and stimulates demand for exports, increasing the price level and inflation.

Adding monetary policy shocks helps bring the model's implications for inflation back into line with the data. During the 2010-2014 period, austere countries tended to have interest rates above the level suggested by the Taylor rule. These high interest rates reduce consumption and output, push down inflation and result in an appreciation of the nominal exchange rate. Thus, for our sample of economies with floating exchange rates, the combination of government spending shocks and contractionary monetary policy shocks results in deflation.

\subsection{Variations on the Benchmark Model}

Table 6 reports the results of simulations under alternative parameterizations of the model, holding the shock processes the same as in the benchmark case. For each simulation, we report the cross-sectional multiplier for GDP and inflation as well as the correlation and standard deviation of simulated GDP relative to the GDP in the data.

We consider the following alternative cases:

(i.) No hand-to-mouth consumers. This specification is the benchmark specification but with the share of hand-to-mouth consumers to $\chi=0$.

(ii.) Separable preferences. Instead of GHH preferences used in the benchmark model, we switch the household's utility function to

$$
U\left(c_{n}, L_{n}\right)=\frac{\left(c_{n}\right)^{1-\frac{1}{\sigma}}}{1-\frac{1}{\sigma}}-\kappa_{n} \frac{\left(L_{n}\right)^{1+\frac{1}{\eta}}}{1+\frac{1}{\eta}}
$$

Unlike GHH, this specification implies that consumption and labor are not complements.

(iii.) Low Price Rigidities. We reset the price rigidity Calvo parameter to $\theta=0.25$ (quarterly). This implies an average duration of prices of roughly 4 months.

(iv.) Wage Rigidities. We introduce sticky wages as in Erceg, Henderson and Levin (2000) (see the Appendix for additional details). We set the wage Calvo parameter to $\theta_{w}=0.80$ (quarterly). This implies an average duration of wages of roughly 15 months.

(v.) Passive Monetary Policy. The monetary authority for each country adopts a more accommodative stance. In particular, we set the Taylor rule coefficients for each country to 
$\phi_{G D P}=\phi_{\pi}-1=0.1$ compared to the benchmark settings of $\phi_{G D P}=\phi_{\pi}-1=0.5$.

(vi.) ZLB. The ECB policy rate is fixed at zero while the other countries are away from the bound. We introduce the ZLB into the model by adding a (large) fictional country to the euro area that sets interest rates for the euro area but doesn't trade with any country. This fictional country is sufficiently large to ensure that changes in inflation and economic activity within Europe do not have a perceptable feedback on the interest rate. The ZLB is assumed to persist indefinitely in this policy experiment.

(vii.) Strong Financial Accelerator. We set the elasticity of the external finance premium to $F_{\varepsilon}=0.8$. Thus, holding the value of capital fixed, a one percent increase in net worth entails a reduction in the external finance premium of 80 basis points.

(viii.) No Euro. This specification allows the countries in the euro area to have floating exchange rates with independent monetary policy and thus to react to local shocks.

(ix.) No Trade. This setting eliminates all trade across countries and thus, the countries interact only because of common monetary policies and correlated shocks.

(x.) High Trade Elasticity. The high trade elasticity sets the parameter $\psi_{y}=5$ relative to the benchmark setting of 0.5. Setting the trade elasticity higher makes foreign and domestic intermediate goods closer substitutes.

A comparison of the multipliers on GDP and inflation across the different cases gives a sense of which features of the model are critical for generating relationships between austerity, output and inflation that match the data. Increased wage rigidity, passive monetary policy and a stronger financial accelerator have little impact on the magnitude of the cross-sectional multipliers. Imposing incomplete markets (not reported) also has little impact on the benchmark results. However, a large fraction of hand-to-mouth consumers and GHH preferences are critical for generating a large multiplier. Trade also plays an important role. Greater substitutability between home and foreign goods weakens the impact of a home austerity shock on output, and increases the spillover to its trading partners. In the extreme case of autarky (the "no trade" case in the last column), the multiplier on GDP increases from 1.95 to 3.85 (thanks to the higher multiplier for fixed exchange rate countries, and despite the lower multiplier for floating exchange rate countries), and the inflation multiplier increases by a factor of 10 .

The addition of the ZLB to the model actually decreases the cross-sectional multiplier on GDP relative to the benchmark. At first pass, this is somewhat surprising. A number of 
studies find that there is a larger response of output to government spending shocks at the ZLB because monetary policy cannot be used to offset the impact of the fiscal shock (see e.g. Blanchard, Erceg and Lindé, 2016; Kilponen et al., 2015). Figure 4 shows the cross-sectional relationship between shortfalls in government purchases and GDP in both our benchmark model (solid dots) and the benchmark specification with the ZLB (open dots). The response of GDP to government spending is indeed greater under the ZLB. For instance, Italy experienced a reduction in government spending of roughly 3 percent of GDP. Away from the ZLB, Italy's GDP falls by roughly 6 percent (a multiplier of approximately 2). At the ZLB, the decline is more than 10 percent (a multiplier of approximately 3). However, while the time-series multipliers are greater at the ZLB, the cross-sectional multipliers are essentially unchanged i.e., the slope of the regression lines in the figure are essentially identical. As emphasized by Nakamura and Steinsson (2014), in a monetary union, the monetary policy reaction is governed by the average GDP and inflation paths for the union as a whole, not by the experiences of individual countries. In our model, if the nominal interest rate is away from the ZLB, then the ECB will respond to aggregate output and inflation for the union as a whole. From the perspective of the simulated scatter plot, the offsetting monetary policy limits the drop in output for all of the solid dots but this policy has no effect on the cross-sectional variation in economic performance.

\section{Counterfactual Policy Simulations}

We next use the model as a laboratory for analyzing three counterfactual scenarios: the elimination of austerity, floating exchange rates, and the dynamics of debt-to-GDP with and without austerity. Figure 5 shows the results of the three scenarios. The top row shows the impact on the EU10 and the bottom row shows the impact on the GIIPS economies.

A World Without Austerity The first counterfactual experiment (the leftmost panels in Figure 5) shows the effect of eliminating spending-based austerity throughout Europe. Specifically, this "No Austerity" experiment removes all negative government spending shocks from the benchmark model but retains any positive shocks. During the 2010 to 2014 period, with the exception of Switzerland, there was virtually no positive fiscal stimulus in Europe. In this experiment, both the benchmark model and the counterfactual simulation without austerity impose the ZLB. We do this because, while the ZLB has only a minimal impact on 
the cross-sectional performance of the model, it has a much larger impact on the time series paths produced by the model. Notice that in the figure, the data display a sharp downturn in GDP in 2008-2009 while the model predicts an expansion. The expansion in the model is due to stimulative monetary and fiscal policy shocks which are reflected in the forcing variables we feed in. The model does not include the collapse in house prices, and credit market failures that led to the Great Recession. Our focus is on the post crisis period starting in 2010.

The figures underscore our main result which is that fiscal austerity has large contractionary effects on output. The benchmark model under the ZLB tracks the data reasonably well, particularly for the GIIPS economies. Actual GDP falls by almost 18 percent in the GIIPS economies and by 15 percent in the benchmark model. When all negative fiscal shocks are eliminated from the model, output in the EU10 is greater than the benchmark by roughly 5 percent. Output for the GIIPS economies would have declined by only one percent rather than the 18 percent that actually occurred. ${ }^{26}$

A World Without the Euro The middle panels in Figure 5 show output trajectories for a "No Euro" experiment. In this counterfactual, the countries experienced austerity shocks but were free to pursue independent monetary policy and allow their currencies to float. ${ }^{27}$ While there are many ramifications of such an "exit strategy" from the euro that are not captured in our model, the experiment does provide some insight into the opportunity cost of a shared monetary policy. Although the effects of allowing countries to pursue independent monetary policy are more modest than eliminating austerity, they do suggest that the GIIPS economies would benefit from moving to independent monetary policy while the EU10 economies would not. This is because the nominal exchange rate depreciates in the GIIPS region, stimulating exports and output. In contrast, under the euro, the EU10 already enjoys the export advantage of a relatively weak currency (at least relative to the non-euro markets) due to the poor performance in the rest of the euro area.

Austerity and the Debt-to-GDP Ratio A significant motivation for austerity policies was to slow the escalation of debt-to-GDP ratios that occurred across the euro area (reaching close to 80 percent in the EU10 and 95 percent in the GIIPS countries in 2010). While reductions in government expenditures should, all else equal, reduce deficits and debt levels

\footnotetext{
${ }^{26}$ While we do not include an explicit sovereign risk premium in the model, the financial shocks in the model are correlated with observed sovereign default spreads.

${ }^{27}$ Unlike the previous counterfactual, we do not impose the ZLB for this experiment.
} 
over time, the impact on the debt-to-GDP ratio is not obvious. As our previous analysis shows, reductions in government expenditures may have a negative impact on economic activity, and this will in turn reduce tax revenues. Further, trade linkages and shared monetary policy in Europe mean that fiscal actions in one country will be readily transmitted to neighboring countries, affecting their fiscal positions.

The rightmost panels in Figure 5 compares the trajectories of debt-to-GDP ratios for the EU10 and GIIPS under different assumptions. The grey line shows the actual data. The light dotted line is a "static" estimate that assumes that GDP and tax revenue are unaffected by changes in government purchases (i.e. reductions in government spending reduce debt but have no impact on the rest of the economy). According to this measure, austerity undertaken by the GIIPS countries should have resulted in a decline in the debt-to-GDP ratios by more than 20 percentage points from 2008 to 2014 . In reality, debt-to-GDP ratios rose by 20 percentage points. This static view misses three endogenous responses captured by our model: First, reductions in government purchases cause reductions in GDP. Second, reductions in GDP lead to reductions in tax revenue. Both of these effects lead to an increase in the debt-toGDP ratio. Third, some of the fiscal austerity will spillover into other countries. ${ }^{28}$ Taking these channels into account (the "benchmark" series), our model actually predicts an increase in the debt-to-GDP ratio in the GIIPS region, of a magnitude similar to that observed in the data. The fit of our model is surprisingly good given that our model assumes that tax rates did not change over time.

Our final experiment considers how debt-to-GDP ratios would have evolved if no austerity measures had been implemented. To answer this question, we simulate our model under the assumption that there were no negative shocks to government purchases. The model predicts a more modest increase in the debt-to-GDP ratio for GIIPS countries. Interestingly, the EU10 countries would have also seen their debt-to-GDP ratios rise, although under the benchmark, their debt-to-GDP ratios went down. The decrease in the debt-to-GDP for the GIIPS countries stems from a strong increase in GDP in the absence of negative fiscal shocks. This effect is weaker for the EU10 countries because their baseline government purchases shocks were not as severe as those experienced by the GIIPS countries. The improved performance of the GIIPS countries leads to a contractionary monetary policy response for the euro area overall,

\footnotetext{
${ }^{28}$ Another channel through which austerity might affect the debt-to-GDP ratio is its effect on sovereign risk premia. Our model ignores this channel. Consequently, the data and simulated data in Figure 5 refer to changes in the cumulative sum of the primary balance, that is the evolution of debt excluding interest payments.
} 
depressing GDP across the region. This effect is sufficiently strong for the EU10 countries that their debt-to-GDP ratio increases. While we do not take the results of the model literally as a prescription for the European debt crisis, the model suggests that efforts to reduce debt through austerity in the depths of an economic recession were counterproductive.

\section{Conclusion}

Since the end of the Great Recession in 2009, advanced economies have experienced radically different recoveries. Some enjoyed a return to normal economic growth following the financial crisis while others have suffered through prolonged periods of low employment and low growth. We have attempted to make sense of this diversity of experiences by examining crosscountry variation in economic activity empirically and through the lens of a dynamic general equilibrium model. Despite substantial noise in the data, there are clear patterns that suggest that an important fraction of the differences in economic performance can be attributed to fiscal austerity. In particular, the evidence suggests that contractions in government purchases played a surprisingly large role in reducing output in many countries.

We use a multi-country DSGE model to see whether standard macroeconomic theory can explain the observed changes in economic activity. The model features government purchases shocks, monetary shocks, and shocks to financial markets and allows us to make direct comparisons between the observed empirical relationships in the data and the model's predictions. The model is calibrated to match the main features of the European countries in our dataset including country size, trade flows and exchange rate regimes. The model output broadly matches the patterns observed in the data. In particular, the model successfully reproduces a large cross-sectional multiplier of government austerity shocks on output.

We use the model to conduct a number of counterfactual experiments. Our analysis suggests that austerity was a substantial drag on GDP, especially for the GIIPS countries. Economic integration shaped the GDP response to austerity in opposite ways: on the one hand, trade integration redistributed its negative consequences across euro area countries, on the other hand, the single monetary policy accentuated the impact of different fiscal policies. Our analysis also suggests that had countries in the euro area abstained from negative fiscal shocks, output would have been substantially higher and may have resulted in lower debt-toGDP ratios across European nations. 


\section{References}

Alesina, Alberto, Carlo Favero, and Francesco Giavazzi. 2015. "The Output Effect of Fiscal Consolidation Plans." Journal of International Economics, 96: S19-S42.

Alesina, Alberto, Gualtiero Azzalini, Carlo Favero, Francesco Giavazzi, and Armando Miano. 2016. "Is it the "How" or the "When" that Matters in Fiscal Adjustments?" National Bureau of Economic Research.

Alvarez, Luis J., Emmanuel Dhyne, Marco Hoeberichts, Claudia Kwapil, Hervé Bihan, Patrick Lünnemann, Fernando Martins, Roberto Sabbatini, Harald Stahl, Philip Vermeulen, et al. 2006. "Sticky Prices in the Euro Area: A Summary of New Micro Evidence." Journal of the European Economic Association, 4(2-3): 575-584.

Backus, David K., Patrick J. Kehoe, and Finn E. Kydland. 1992. "International Real Business Cycles." Journal of Political Economy, 100(4): 745-775.

Backus, David K., Patrick J. Kehoe, and Finn E. Kydland. 1994. "Dynamics of the Trade Balance and the Terms of Trade: The J-Curve?" American Economic Review, 84(1): 84-103.

Barro, Robert J., and Charles J. Redlick. 2009. "Macroeconomic Effects From Government Purchases and Taxes." Quarterly Journal of Economics, 126(1): 51-102.

Barsky, Robert B., F. Thomas Juster, Miles S. Kimball, and Matthew D. Shapiro. 1997. "Preference Parameters and Behavioral Heterogeneity: An Experimental Approach in the Health and Retirement Study." Quarterly Journal of Economics, 112(2): 537-579.

Beraja, Martin, Erik Hurst, and Juan Ospina. 2014. "The Regional Evolution of Prices and Wages During the Great Recession."

Beraja, Martin, Erik Hurst, and Juan Ospina. 2016. "The Aggregate Implications of Regional Business Cycles." NBER Working Paper, No.21956.

Bernanke, Ben S., Mark Gertler, and Simon Gilchrist. 1999. "The Financial Accelerator in a Quantitative Business Cycle Framework." In Handbook of Macroeconomics. Vol. 1, , ed. John B. Taylor and Michael Woodford, 1341-1393. Elsevier. 
Blanchard, Oliver, and David Leigh. 2013. "Growth Forecast Errors and Fiscal Multipliers." American Economic Review: Papers and Proceedings, 103(3): 117-120.

Blanchard, Olivier, Christopher Erceg, and Jesper Lindé. 2016. "Jump-Starting the Euro Area Recovery: Would a Rise in Core Fiscal Spending Help the Periphery?" In NBER Macroeconomics Annual 2016, Volume 31. University of Chicago Press.

Brave, Scott A., Jeffrey R. Campbell, Jonas D. M. Fisher, and Alejandro Justiniano. 2012. "The Chicago Fed DSGE Model." Working Paper.

Broda, Christian, Joshua Greenfield, and David Weinstein. 2006. "From Groundnuts to Globalization: A Structural Estimate of Trade and Growth." NBER Working Paper, No. 12512.

Burstein, Ariel, and Gita Gopinath. 2014. "International Prices and Exchange Rates." In Handbook of International Economics. Vol. 4. Elsevier.

Campbell, John Y., and N. Gregory Mankiw. 1989. "Consumption, Income and Interest Rates: Reinterpreting the Time Series Evidence." In NBER Macroeconomics Annual 1989, Volume 4. 185-246. MIT Press.

Carlstrom, Charles T., and Timothy Fuerst. 1997. "Agency Costs, Net Worth, and Business Fluctuations: A Computable General Equilibrium Analysis." American Economic Review, 87(5): 893-910.

Chari, V.V., Patrick J. Kehoe, and Ellen R. McGrattan. 2000. "Sticky Price Models of the Business Cycle: Can the Contract Multiplier Solve the Persistence Problem?" Econometrica, 68(5): 1151-1179.

Chow, Gregory C., and Anloh Lin. 1971. "Best Linear Unbiased Interpolation, Distribution, and Extrapolation of Time Series by Related Series." Review of Economics and Statistics, 372-375.

Christiano, Lawrence J., Martin Eichenbaum, and Charles L. Evans. 2005. "Nominal Rigidities and the Dynamic Effects of a Shock to Monetary Policy." Journal of Political Economy, 113(1): 1-45.

Christiano, Lawrence J., Roberto Motto, and Massimo Rostagno. 2014. "Risk Shocks." American Economic Review, 104(1): 27-65. 
Clarida, Richard, Jordi Gali, and Mark Gertler. 1997. "The Science of Monetary Policy: A New Keynesian Perspective." Journal of Economic Literature, 37: 1667-1707.

Cravino, Javier. 2014. "Exchange Rates, Aggregate Productivity and the Currency of Invoicing of International Trade." Working Paper.

Del Negro, Marco, Stefano Eusepi, Marc Giannoni, Argia Sbordone, Andrea Tambalotti, Matthew Cocci, Raiden Hasegawa, and M. Henry Linder. 2013. "The FRBNY DSGE Model." Federal Reserve Bank of New York Staff Report No. 647.

Erceg, Christopher J., and Jesper Lindé. 2013. "Fiscal Consolidation in a Currency Union: Spending Cuts vs. Tax Hikes." Journal of Economic Dynamics and Control, 37(2): 422-445.

Erceg, Christopher J., Dale W. Henderson, and Andrew T. Levin. 2000. "Optimal Monetary Policy with Staggered Wage and Price Contracts." Journal of Monetary Economics, 46(2): 281-313.

Eurostat. 2014. "Taxation Trends in the European Union - Data for the EU Member States, Iceland and Norway."

Gopinath, Gita, and Oleg Itskhoki. 2011. "In Search of Real Rigidities." In NBER Macroeconomics Annual 2010. Vol. 25. Chicago:University of Chicago Press.

Greenwood, Jeremy, Zvi Hercowitz, and Gregory W. Huffman. 1988. "Investment, Capacity Utilization, and the Real Business Cycle." American Economic Review, 402-417.

Hall, Robert E. 2009. "By How Much Does GDP Rise If the Government Buys More Output?" Borrkings Papers on Economic Activity, Fall: 183-236.

Heathcote, Jonathan, and Fabrizio Perri. 2002. "Financial Autarky and International Real Business Cycles." Journal of Monetary Economics, 49(3): 601-627.

Itzetzki, Ethan O., Carmen M. Reinhart, and Kenneth Rogoff. 2004. "Exchange Rate Arrangenents until the 21st Century: Will the Anchor Currency Hold?" Working Paper.

Kilponen, Juha, Massimiliano Pisani, Sebastian Schmidt, Vesna Corbo, Tibor Hlédik, Josef Hollmayr, Samuel Hurtado, Paulo Júlio, Dmitry Kulikov, 
Matthieu Lemoine, et al. 2015. "Comparing Fiscal Multipliers Across Models and Countries in Europe." European Central Bank.

Klenow, Peter J., and Oleksiy Kryvtsov. 2008. "State-Dependent or Time-Dependent Pricing: Does It Matter for Recent US Inflation?" Quarterly Journal of Economics, 123(3): 863-904.

Martin, Philippe, and Thomas Philippon. 2016. "Inspecting the Mechanism: Leverage and the Great Recession in the Eurozone." NBER Working Paper, No. 20572.

Mendoza, Enrique G., Assaf Razin, and Linda L. Tesar. 1994. "Effective Tax Rates in Macroeconomics: Cross-Country Estimates of Tax Rates on Factor Incomes and Consumption." Journal of Monetary Economics, 34(3): 297-323.

Nakamura, Emi, and Jón Steinsson. 2008. "Five Facts About Prices: A Reevaluation of Menu Cost Models." Quarterly Journal of Economics, 123(4): 1415-1464.

Nakamura, Emi, and Jon Steinsson. 2014. "Fiscal Stimulus in a Monetary Union: Evidence from US Regions." American Economic Review, 104(3): 753-792.

Proebsting, Christian. 2015. "Are Devaluations Expansionary? - Firm-Level Evidence from Estonia." Working Paper.

Ramey, Valerie A., and Sarah Zubairy. 2014. "Government Spending Multipliers in Good Times and in Bad: Evidence from US Historical Data." NBER Working Paper, No. 20719.

Romer, Christina D., and David H. Romer. 2004. "A New Measure of Monetary Shocks: Derivation and Implications." American Economic Review, 94(4): 1055-1084.

Romer, Christina D., and David H. Romer. 2010. "The Macroeconomic Effects of Tax Changes: Estimates Based on a New Measure of Fiscal Shocks." American Economic Review, 100(3): 763-801.

Smets, Frank, and Rafael Wouters. 2007. "Shocks and Frictions in US Business Cycles: A Bayesian DSGE Approach." American Economic Review, 97(3): 586-606.

Trabandt, Mathias, and Harald Uhlig. 2011. "The Laffer Curve Revisited." Journal of Monetary Economics, 58(4): 305-327. 
Woodford, Michael, and Carl E. Walsh. 2005. Interest and Prices: Foundations of a Theory of Monetary Policy. Cambridge University Press. 


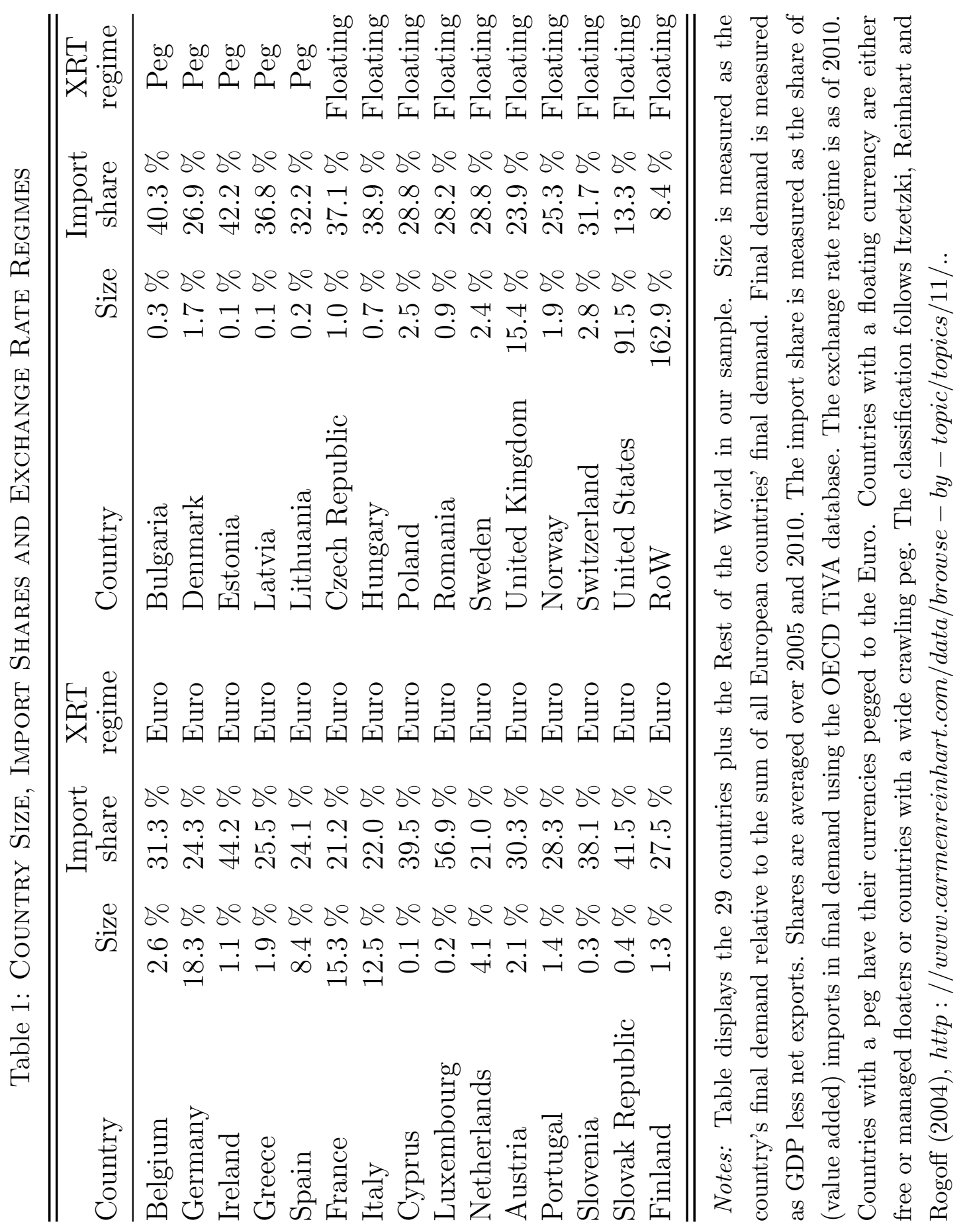




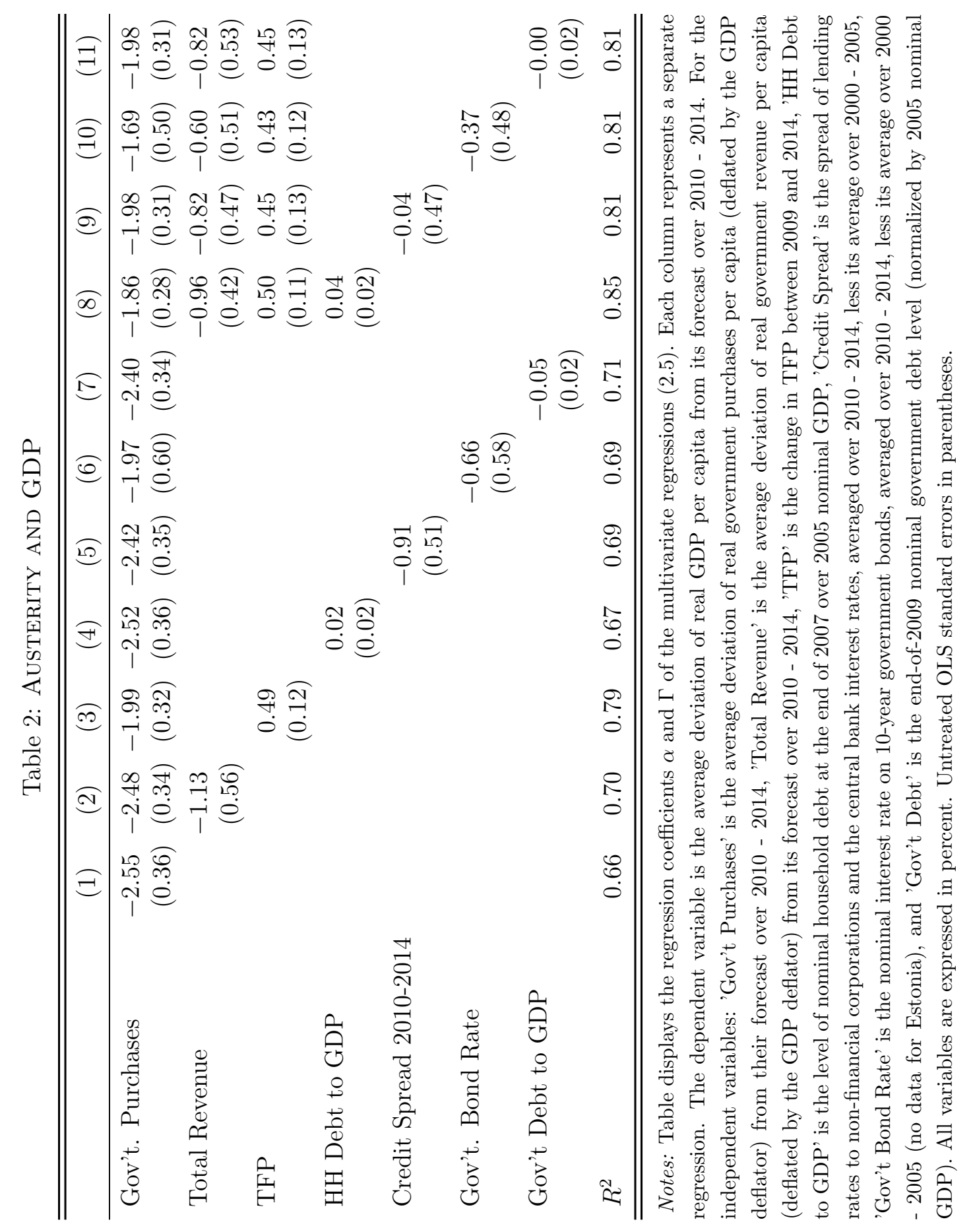


Table 3: Comparison of Model and Data: Benchmark Calibration

\begin{tabular}{|c|c|c|c|c|c|c|}
\hline & \multicolumn{3}{|c|}{ Data } & \multicolumn{3}{|c|}{ Benchmark } \\
\hline & $\alpha$ & $\alpha^{F i x}$ & $\alpha^{F l}$ & $\alpha$ & $\alpha^{F i x}$ & $\alpha^{F l}$ \\
\hline GDP & $\begin{array}{r}-1.98 \\
(0.26)\end{array}$ & $\begin{array}{c}-2.02 \\
(0.32)\end{array}$ & $\begin{array}{r}-1.78 \\
(0.51)\end{array}$ & -1.95 & -2.01 & -1.74 \\
\hline Inflation & $\begin{array}{r}-0.43 \\
(0.13)\end{array}$ & $\begin{array}{r}-0.55 \\
(0.15)\end{array}$ & $\begin{array}{r}-0.18 \\
(0.24)\end{array}$ & -0.26 & -0.29 & -0.13 \\
\hline Consumption & $\begin{array}{r}-1.31 \\
(0.23)\end{array}$ & $\begin{array}{r}-1.36 \\
(0.27)\end{array}$ & $\begin{array}{r}-1.11 \\
(0.44)\end{array}$ & -1.06 & -1.15 & -0.77 \\
\hline Investment & $\begin{array}{c}-1.54 \\
(0.19)\end{array}$ & $\begin{array}{r}-1.64 \\
(0.23)\end{array}$ & $\begin{array}{r}-1.21 \\
(0.37)\end{array}$ & -0.59 & -0.65 & -0.39 \\
\hline Net Exports over GDP & $\begin{array}{r}1.42 \\
(0.24)\end{array}$ & $\begin{array}{r}1.52 \\
(0.27)\end{array}$ & $\begin{array}{r}1.02 \\
(0.44)\end{array}$ & 1.29 & 1.31 & 1.24 \\
\hline Exchange Rate & $\begin{array}{r}-0.91 \\
(0.42)\end{array}$ & $\begin{array}{r}0.47 \\
(0.35)\end{array}$ & $\begin{array}{r}-3.36 \\
(0.57)\end{array}$ & -0.17 & -0.10 & -0.53 \\
\hline GDP Growth & $\begin{array}{c}-0.58 \\
(0.11)\end{array}$ & $\begin{array}{c}-0.55 \\
(0.13)\end{array}$ & $\begin{array}{c}-0.54 \\
(0.20)\end{array}$ & -0.29 & -0.33 & -0.20 \\
\hline
\end{tabular}

Notes: Table displays the regression coefficients on government purchases ( $\alpha$ in regression (2.5) and for the multipliers $\alpha^{F i x}$ and $\alpha^{F l}$ for the regression with separate coefficients for fixed and floating exchange rate countries, after controlling for government revenue, government debt and TFP as is done in specification (11) of Table 2. Each row represents a separate regression. The dependent variables are average forecast errors in real GDP per capita, the inflation rate based on the Harmonized Index for Consumer Prices excluding Food and Energy, real consumption per capita, real investment per capita, real net exports over nominal 2005Q1 GDP, the nominal effective exchange rate and real GDP per capita growth. 


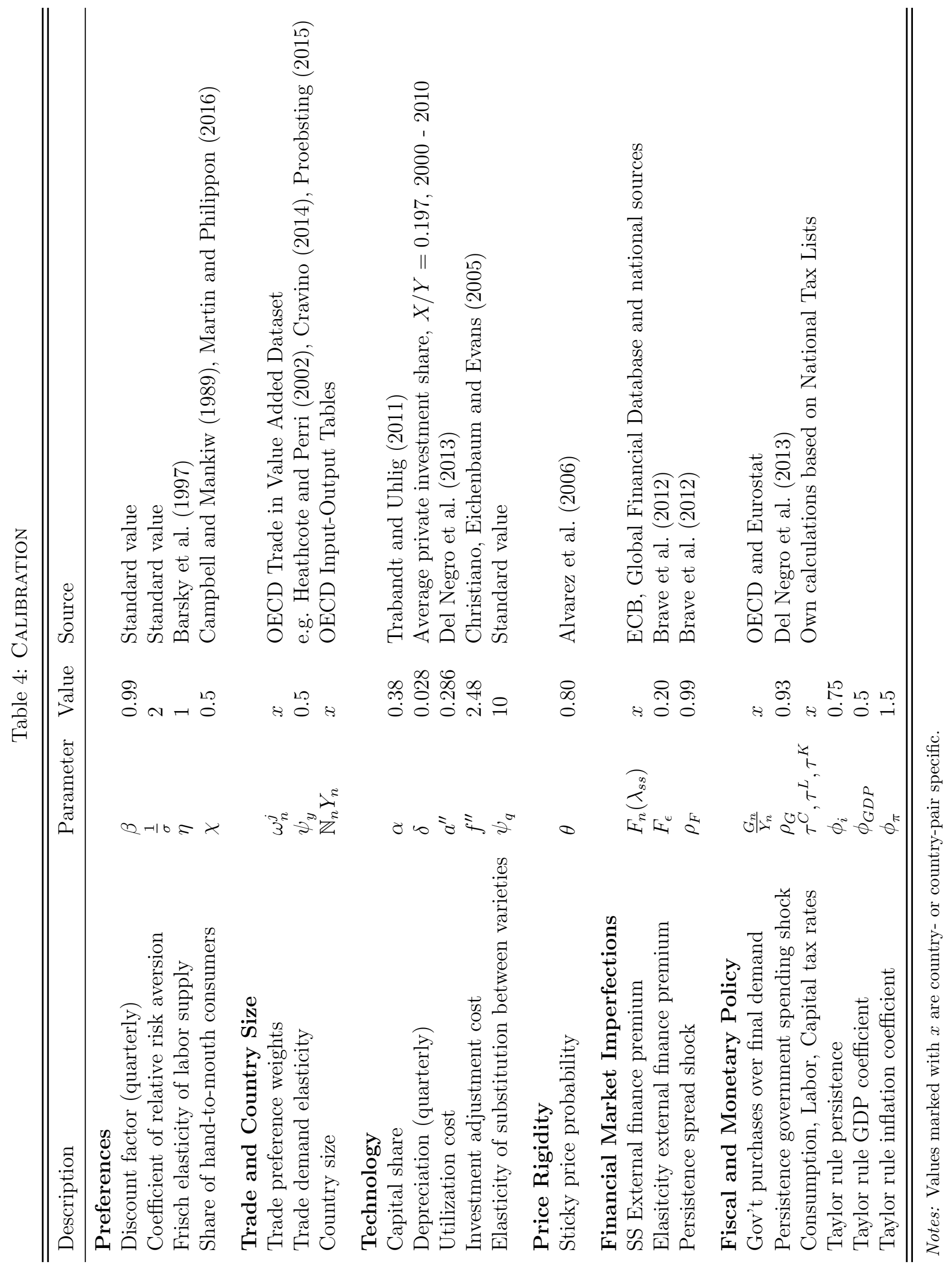


Table 5: Comparison of Model and Data: Individual Shocks

\begin{tabular}{lrrrrr}
\hline \hline & Data & $\begin{array}{c}\text { Bench- } \\
\text { mark }\end{array}$ & $\begin{array}{c}\text { No } \\
\text { Spread }\end{array}$ & $\begin{array}{c}\text { No } \\
\text { Money }\end{array}$ & $\begin{array}{c}\text { Only } \\
\text { Govt }\end{array}$ \\
\hline All & & & & & \\
$\quad$ GDP & -1.98 & -1.95 & -1.90 & -1.85 & -1.79 \\
$\quad$ Inflation & -0.43 & -0.26 & -0.31 & -0.12 & -0.17 \\
Net Exports to GDP & 1.42 & 1.29 & 1.25 & 1.26 & 1.22 \\
& & & & & \\
Fixed & & & & & -1.91 \\
$\quad$ GDP & -2.02 & -2.01 & -1.88 & -2.04 & -0.35 \\
Inflation & -0.55 & -0.29 & -0.34 & -0.30 & -0.32 \\
$\quad$ Net Exports to GDP & 1.52 & 1.31 & 1.23 & 1.30 & 1.22 \\
Floaters & & & & & \\
GDP & -1.78 & -1.74 & -1.90 & -1.34 & -1.50 \\
Inflation & -0.18 & -0.13 & -0.17 & 0.35 & 0.32 \\
Net Exports to GDP & 1.02 & 1.24 & 1.31 & 1.15 & 1.22 \\
Simulated GDP & & & & & \\
Correlation with Data & 1.00 & 0.79 & 0.81 & 0.79 & 0.81 \\
Rel. Std. Dev. & 1.00 & 0.85 & 0.81 & 0.80 & 0.76 \\
\hline \hline
\end{tabular}

Notes: Table displays multiplier, which is the estimated $\alpha$ in regression (2.5) with regressors being fiscal shocks observed in the data. The correlation for simulated GDP is the simple correlation of simulated GDP data averaged over 2010 - 2014 compared to the actual GDP data averaged over 2010 - 2014. Similarly, the relative standard deviation is the standard deviation of simulated GDP averaged over 2010 - 2014 relative to the standard deviation observed in the data for that time period. 


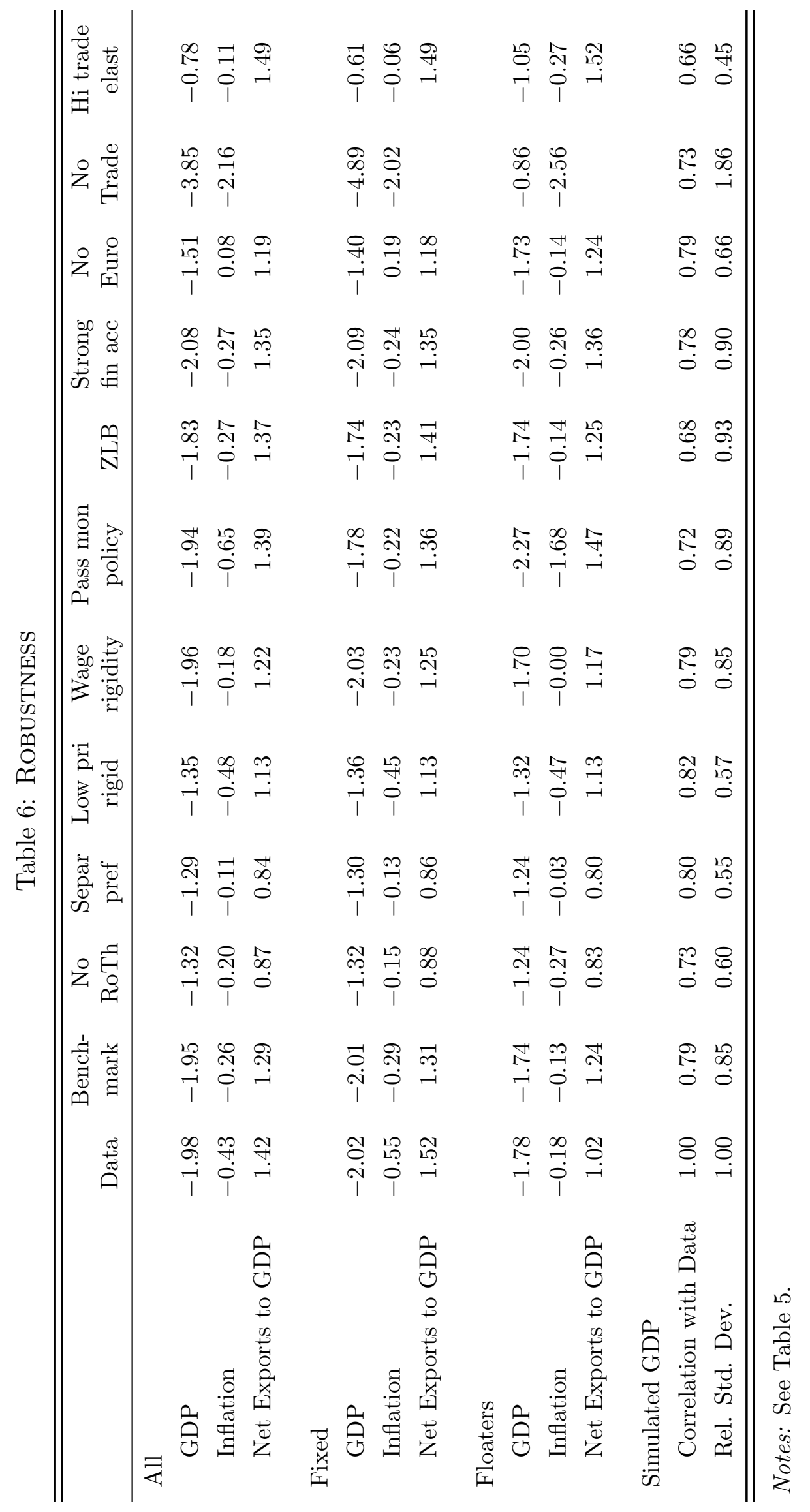




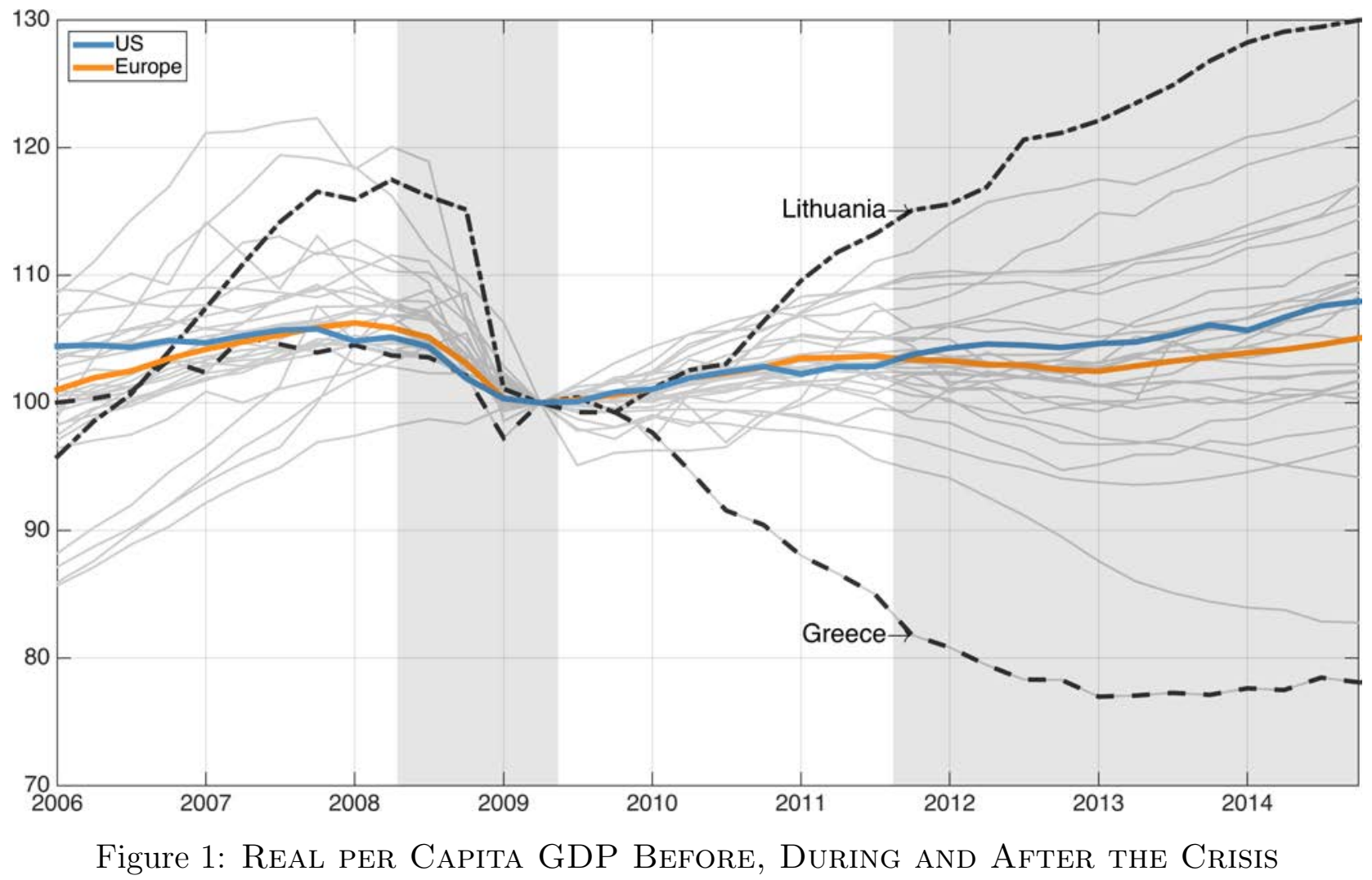

Note: The figure plots the time paths of real per capita GDP for the period 2006:1-2014:4 for the countries in our data set. The paths are indexed to 100 in 2009:2. The two shaded regions indicate recession dates according to the NBER and CEPR. 

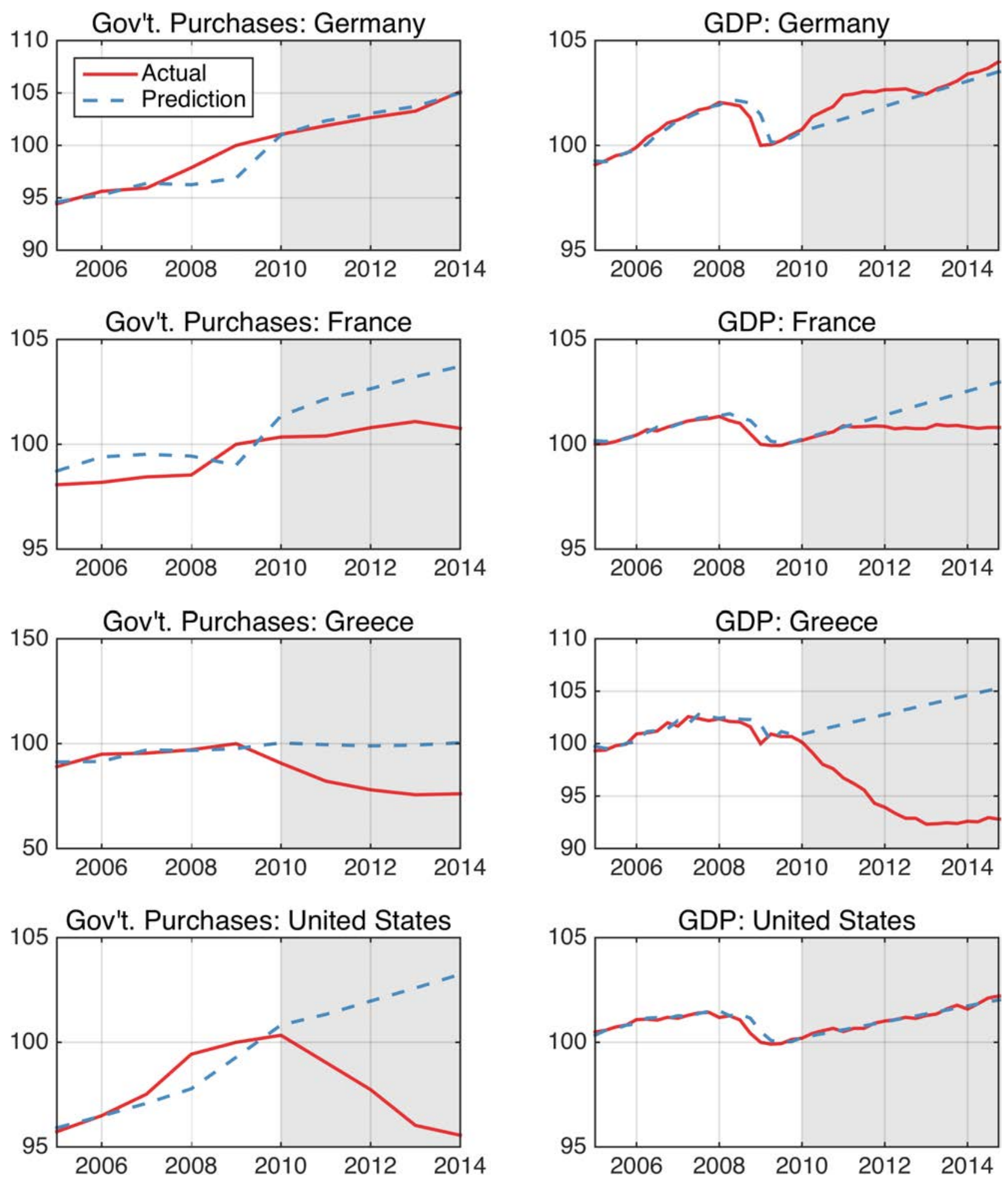

Figure 2: Government Purchases and GDP

Note: Left column panels display real government purchases for various countries on a log scale (normalized to $2009=100$ ), together with their predicted values. Right column panels display the corresponding series for real GDP per capita. 


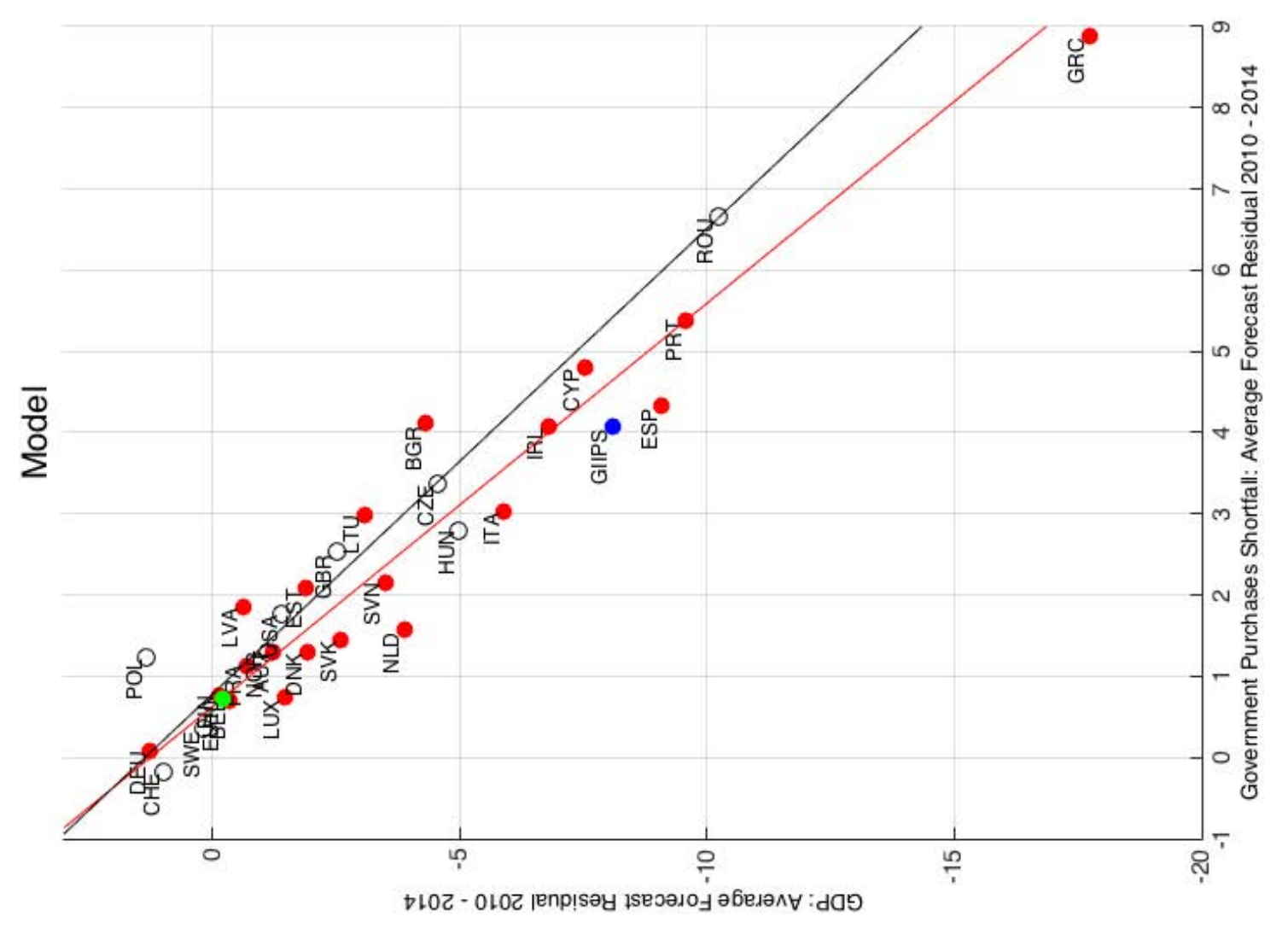

$\because \stackrel{g}{g}$

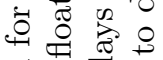

要

可

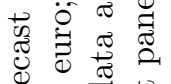

递安

0.

so

둥

욤

क वै

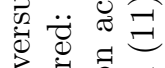

$>$ 혀

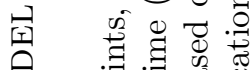

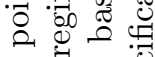

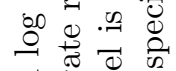

$\dot{n} \quad \exists$ 覀

$>\quad \because D_{0} . \exists$

ङ

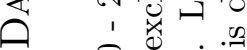

$\because \quad 0$

$\ddot{i} \quad$ ते

究

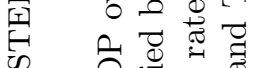

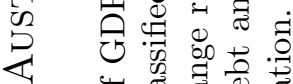

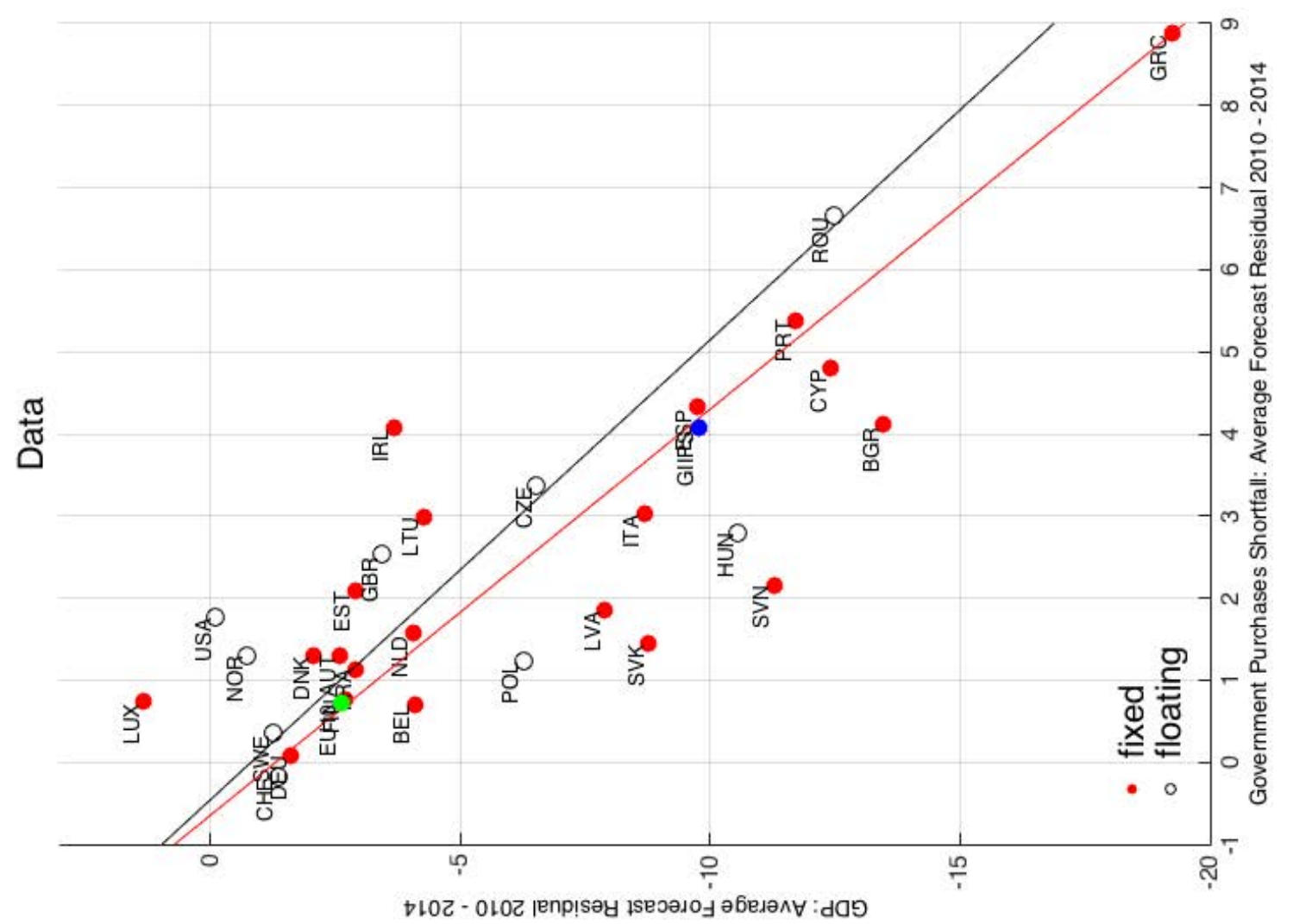

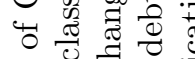

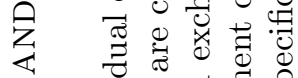

जु की द्व की

क

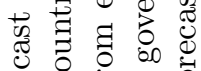

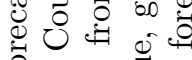

两

․ $\quad$ o

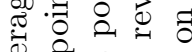

完

․․

岁 0

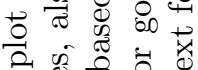

政

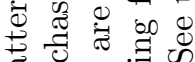

\%

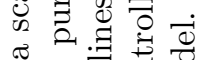

娄

要券.

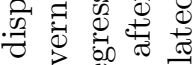

额

.

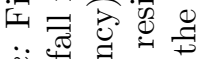

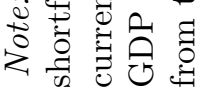




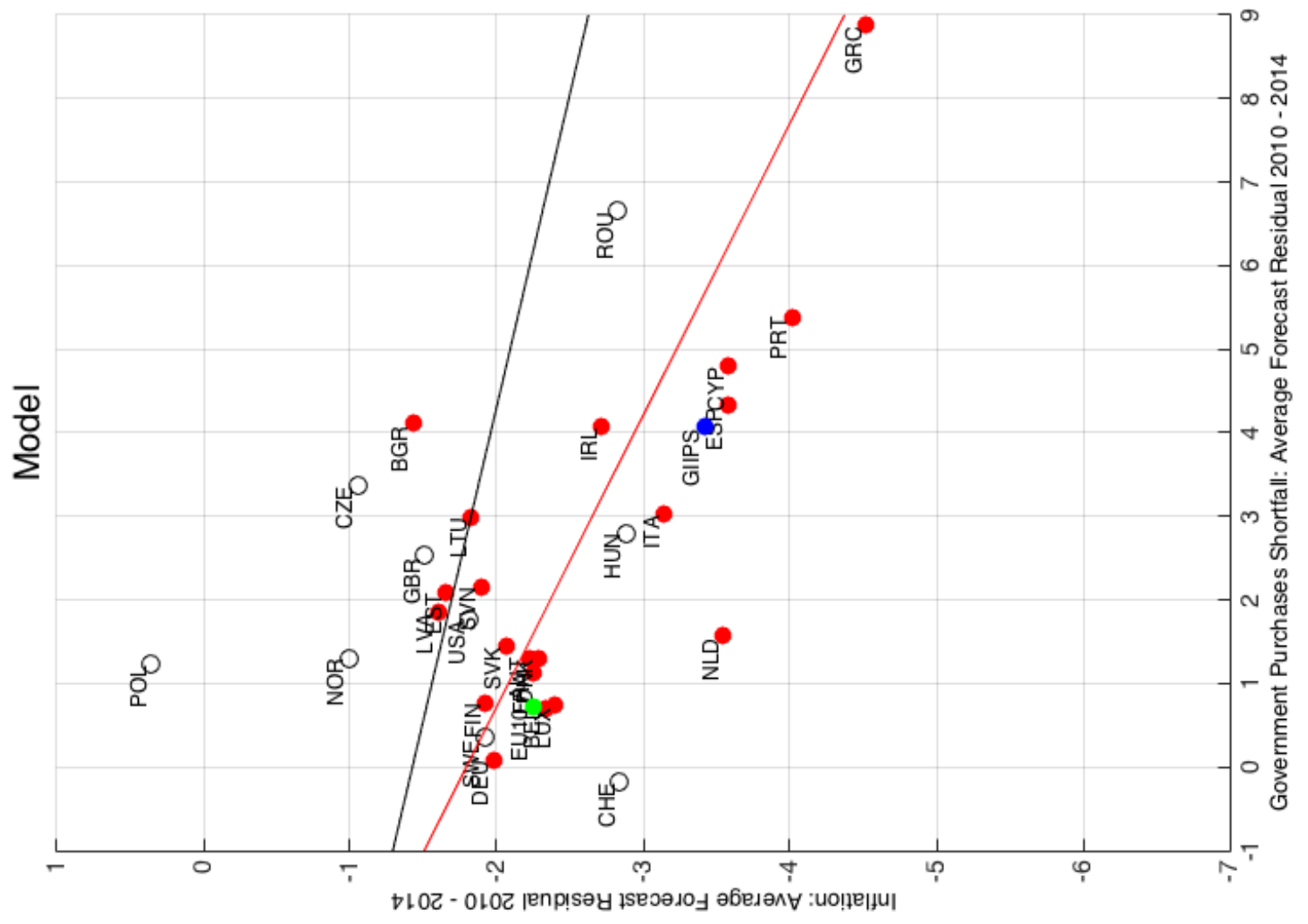

国

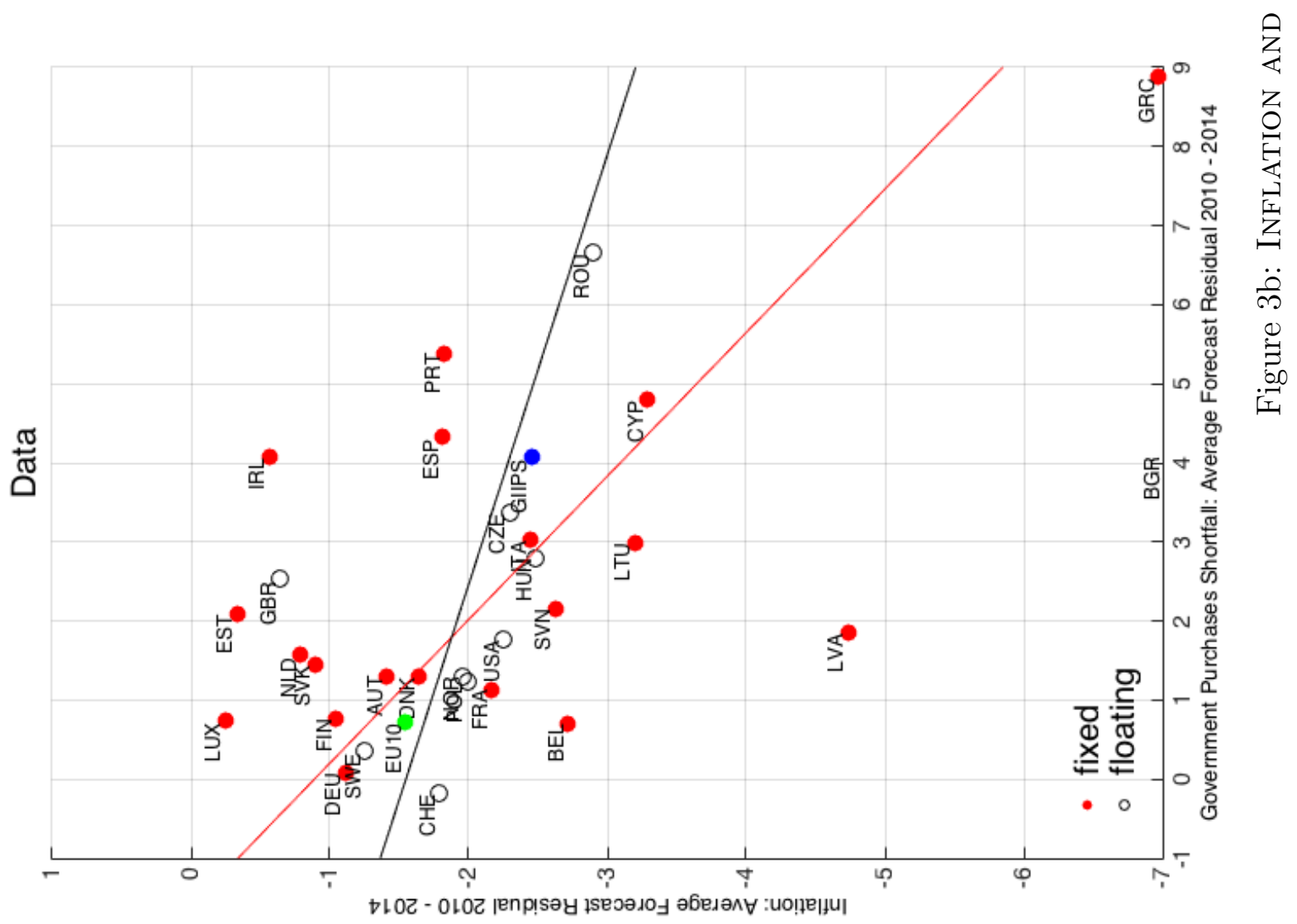

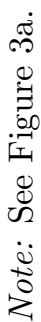




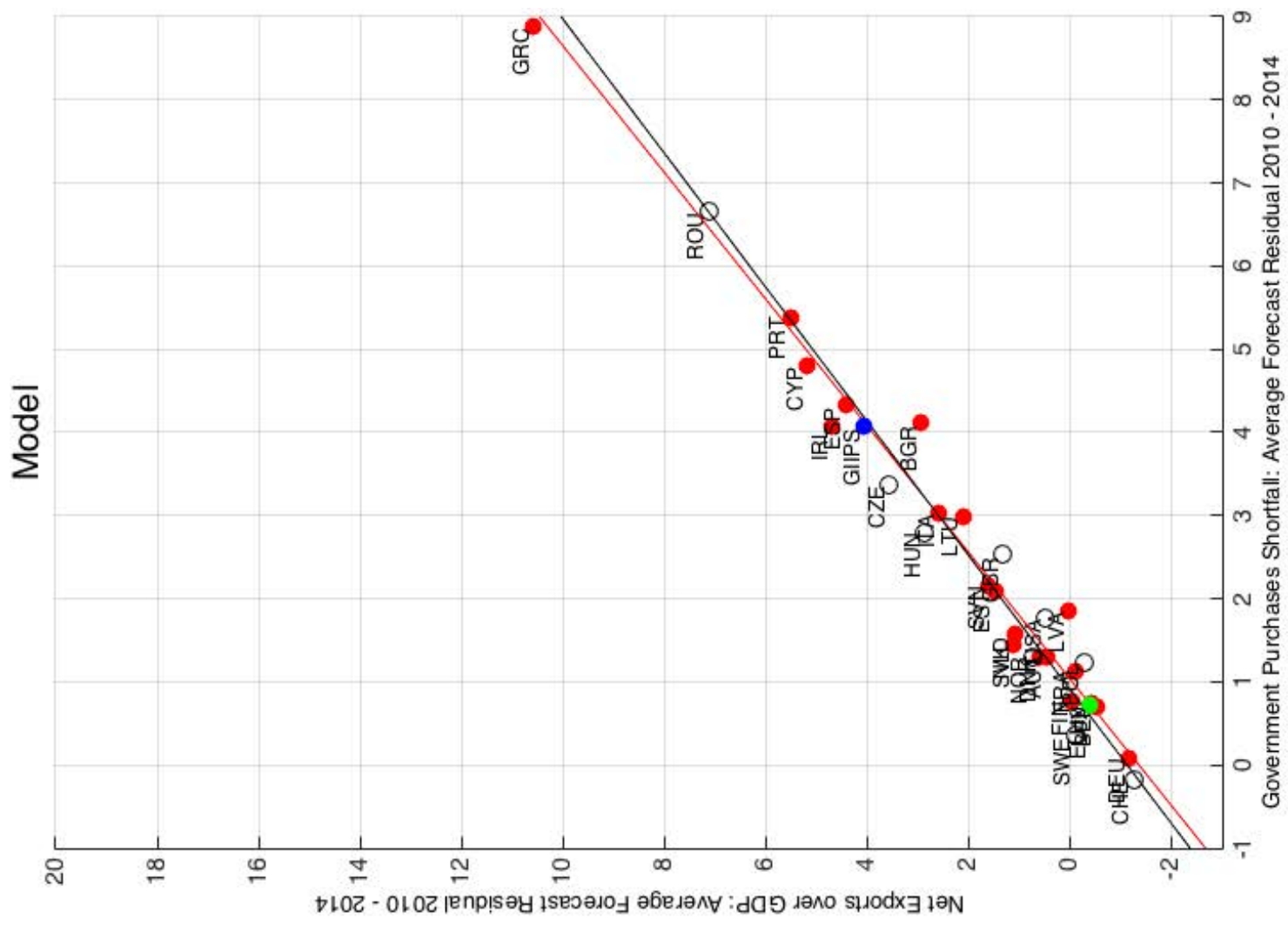

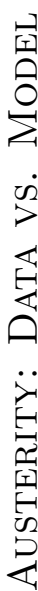

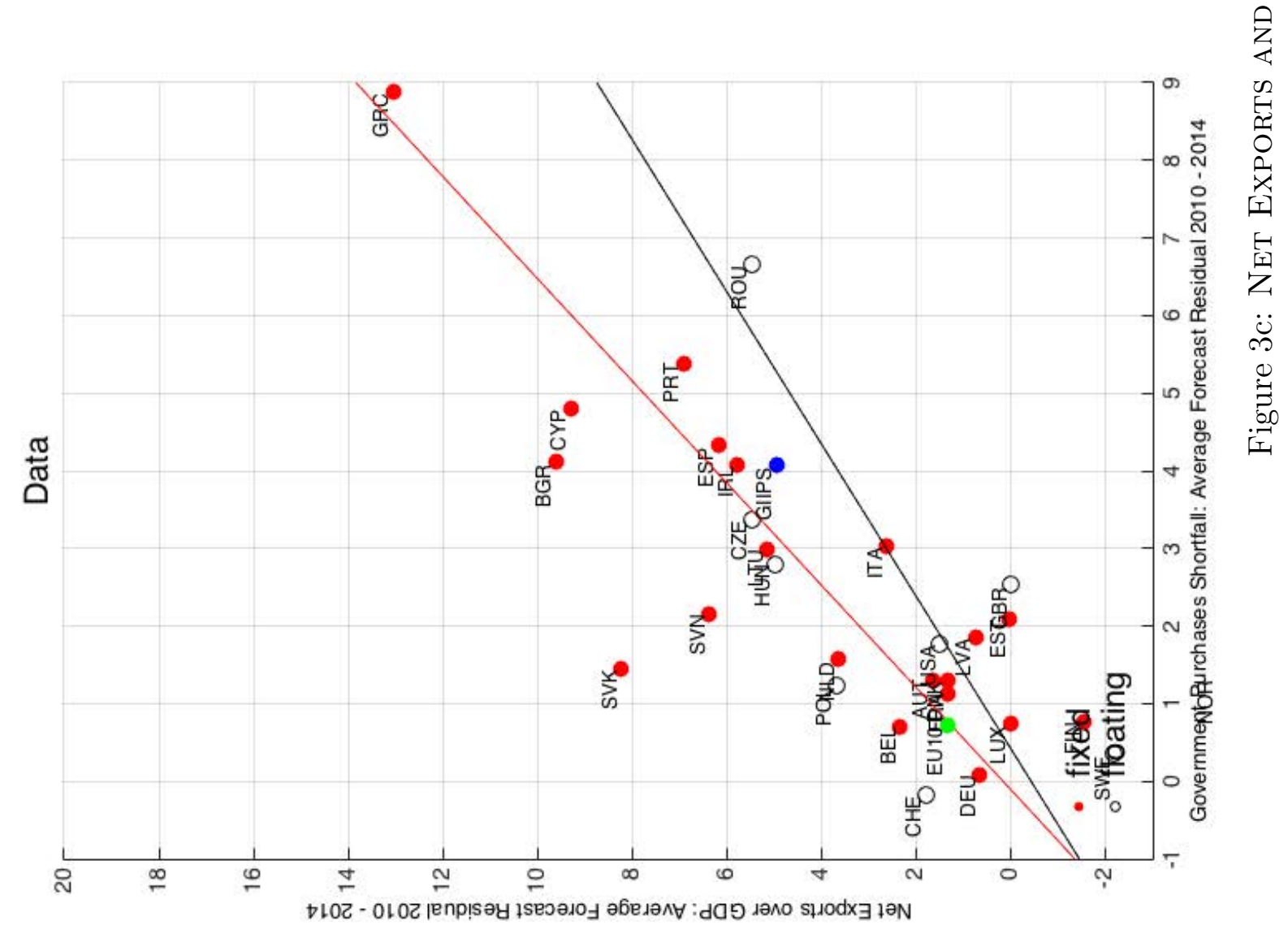

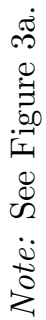




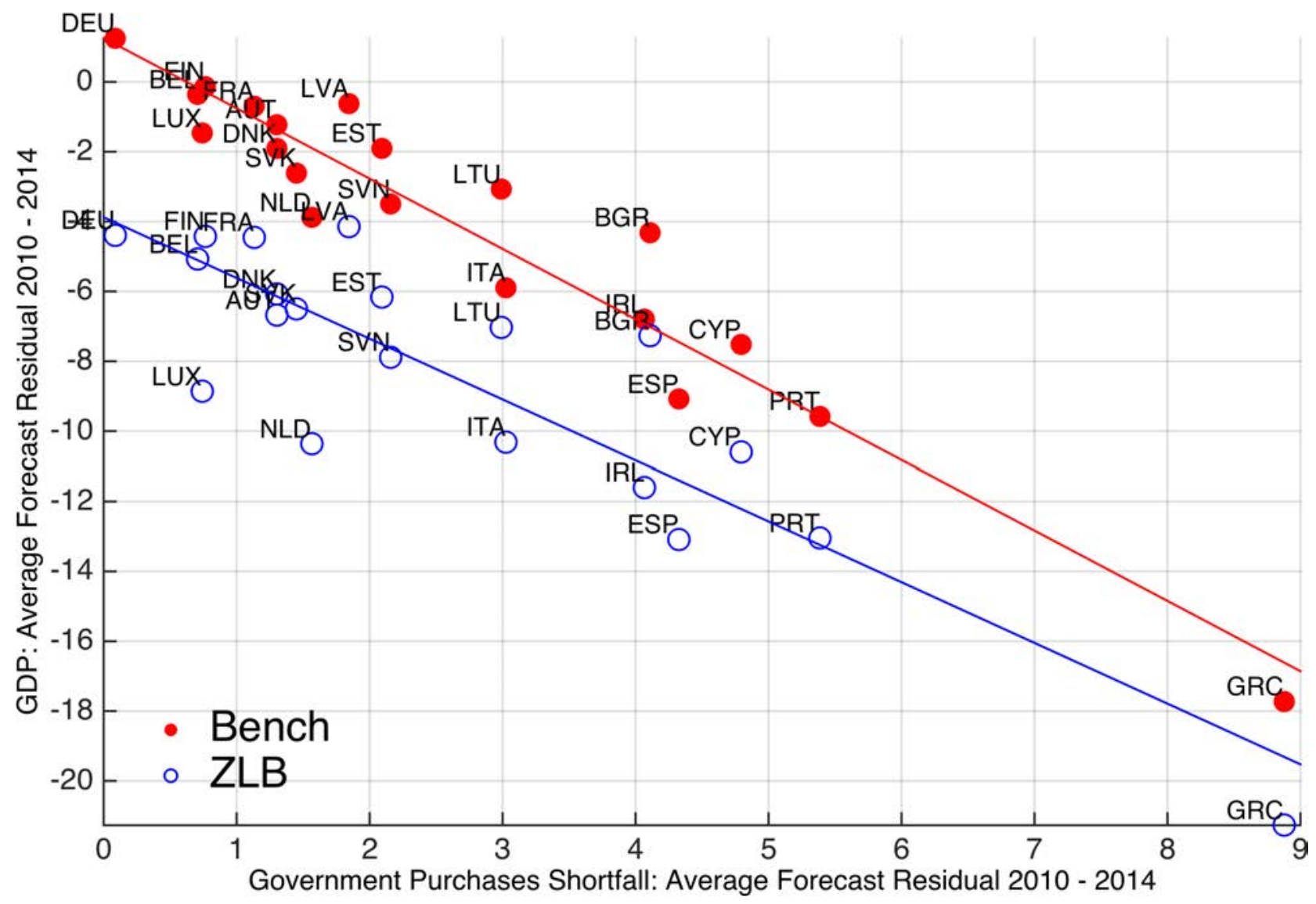

Figure 4: GDP and Government Purchases: Without and With a ZLB

Note: Figure displays a scatter plot of the average forecast residual of GDP over 2010 - 2014, in log points, versus the average forecast residual for the shortfall in government purchases, also in log points. Sample only includes countries with fixed exchange rates. Red dots refer to simulated data under the benchmark calibration; blue dots refer to simulated data under the benchmark calibration with a ZLB for the ECB. 

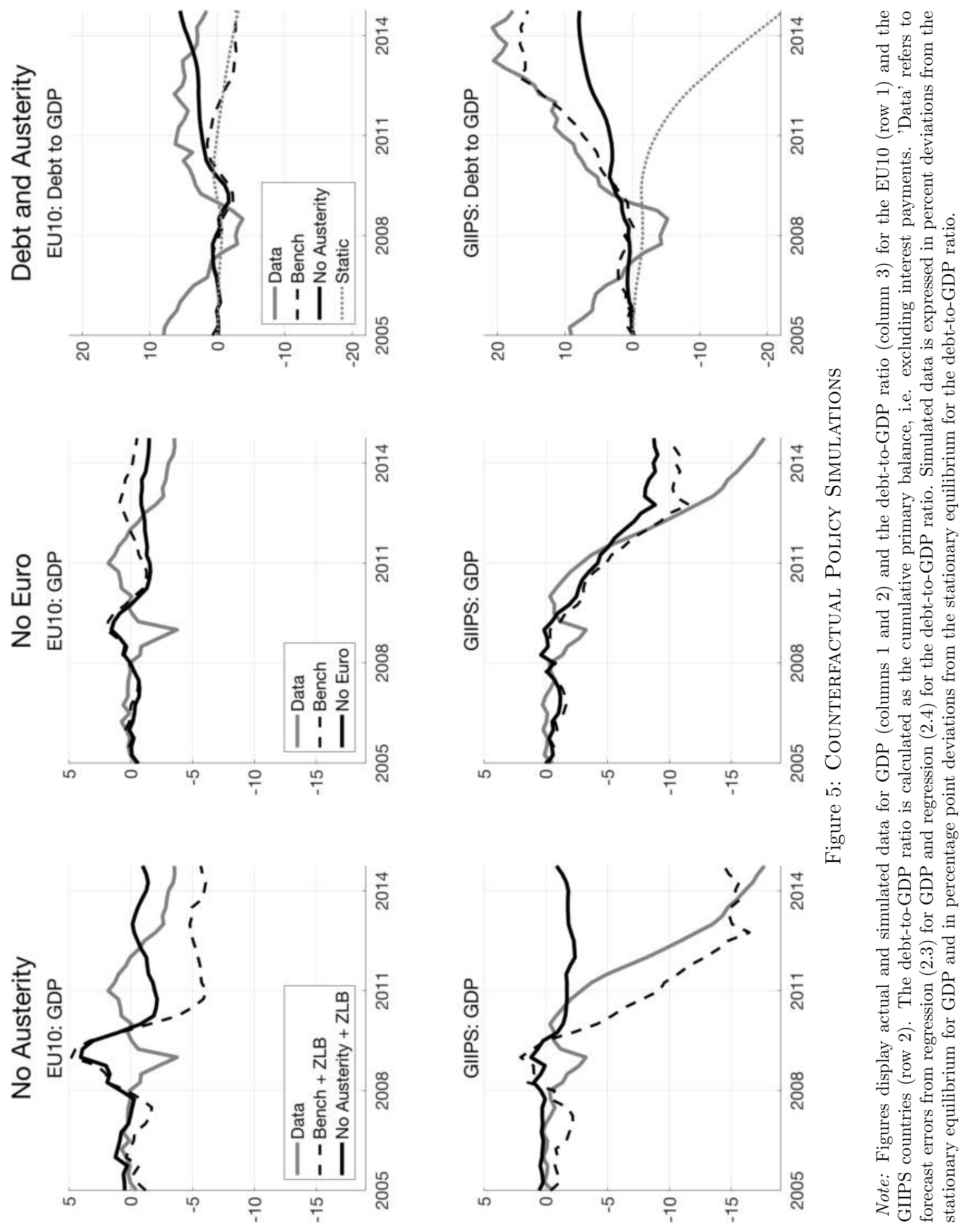